\title{
Informal Cross Border Trade as a \\ Substratum Marketing System: A Review and Conceptual Framework
}

\author{
Eldrede Kahiya' ${ }^{\prime}$ and Djavlonbek Kadirov' ${ }^{\top}$
}

\begin{abstract}
We provide a literature review and a conceptual framework on informal cross border trade in Sub-Saharan Africa. Informal cross border trade (ICBT) refers to commercial exchanges conducted across borders by individuals operating as unregistered sole traders. ICBT is a burgeoning part of the informal markets in Sub-Saharan Africa and its existence and persistence carry substantial socio-economic implications. We use "summarizing" and "delineating" techniques to discuss seven themes of ICBT, and cast them as the manifestations of a substratum marketing system - a foundational structure instead of an auxiliary system. We underline implications for scholarship and for policymakers and non-governmental organizations charged with formulating initiatives to manage both ICBT and formal markets.
\end{abstract}

\section{Keywords}

developing countries, economic development, empowerment, subsistence entrepreneurship, marketing system design, trade routes, vulnerability

\section{Introduction}

We review extant research and offer a conceptual framework on informal cross border trade (ICBT) - commercial exchanges of goods and services by informal traders operating between borders. Although ICBT occurs between countries in other parts of the world including China/North Korea, India/Pakistan, Myanmar/Thailand, USA/Mexico and vast parts of Eastern Europe (see Aung 2009; Hastings and Wang 2018; Pisani and Richardson 2012; Sword 1999; Taneja and Bimal 2017; Xheneti, Smallbone, and Welter 2013), it is ubiquitous in Sub-Saharan Africa. Multiple studies (e.g. Afrika and Ajumbo 2012; Dobler 2016; Ellis and MacGaffey 1996; Fadahunsi and Rosa 2002; Flynn 1997; Meagher 2003; Peberdy and Crush 2001; Peterson and Zehra 2018; Raeymaekers 2012; Tschirley and Jayne 2010) suggest ICBT is part of the socio-economic fabric of SubSaharan Africa which encompasses state fragility, poverty, rural to urban migration, food security, economic reform, inequality, economic empowerment, and formal and informal markets.

Extant research on ICBT (e.g. Akinboade 2005; Ellis and MacGaffey 1996; Golub 2015; Hunter and Skinner 2003; Little, Tiki, and Debsu 2015; Ogalo 2010; Peberdy 2000a; Titeca and Kimanuka 2012; Walther 2012) focuses on individual components of the phenomenon like push-pull factors, sociodemographic profiles of participants, and the institutional and financial barriers traders encounter. To date, ICBT has been the subject of neither comprehensive reviews nor conceptual development. The limited interest in reviewing past research and enhancing conceptual development is surprising given the prevalence of ICBT and the fact that it embodies everyday entrepreneurship (The Economist 2018; Welter et al. 2017). In response to both the calls for more conceptual contribution in marketing and the need for contextualization of theory (see Chandler and Vargo 2011; MacInnis 2011; Peterson and Zehra 2018; Yadav 2010), we explicate on one of the omnipresent but under-researched aspects about Africa. We position our study at the trans-disciplinary intersection (Fisk 2006; Peterson 2006) of base of the pyramid research and macromarketing - an area of increasing importance for the Journal of Macromarketing (see Singh and Bharadwaj 2017). Guided by MacInnis (2011, p. 138), we utilize "summarizing" and "delineating" techniques to expound ICBT. The former appraises past research and identifies seven thematic clusters which encapsulate extant knowledge, while the latter uses the clusters to theorize that informal cross border trade typifies a substratum marketing system.

We conceptualize and map ICBT as a substratum marketing system - a distinctive foundational structure that enables the

\footnotetext{
'Wellington School of Business and Government, Victoria University of Wellington, Wellington, New Zealand
}

\section{Corresponding Author:}

Eldrede Kahiya, Wellington School of Business and Government, Victoria University of Wellington, 23 Lambton Quay, Wellington 6I40, New Zealand. Email: eldrede.kahiya@vuw.ac.nz 
process of formalization (i.e. the emergence and growth of formal marketing systems) (Layton 2015). Previous research (e.g. Layton 2007, 2011) implies ICBT is an auxiliary marketing system (i.e. exchange structures that emerge parallel to formal marketing systems). Likewise, recent public policy suggestions for Africa also tend to uphold this view, treating ICBT as a set of nuisance/burden phenomena that must be uprooted (Afrika and Ajumbo 2012). This view is underscored by a broader perspective of understanding observed marketing systems, where formal marketing systems are seen grounded in social matrix (Hounhouigan et al. 2014; Layton 2011). We offer a different conceptualization in this article - evidence which shows that formal market structures are but a "tip of an iceberg" grounded in a broader substratum of culturally entangled hybrid exchange relationships and practices. This substratum becomes visible, or highlighted as ICBT, when it spans across national borders.

Thus, ICBT can be seen as a manifestation of the bedrock of fundamental marketing systems/provisioning activities in society. This conceptual shift, to our knowledge, is the first attempt to assess ICBT as an all-encompassing system. Previous research on ICBT is mostly micro-level, and efforts to explicate it at the macro-level (e.g. Dobler 2016; Layton 2007; Walther 2009) have addressed subsystems. For instance, Dobler's (2016) conceptualization focuses on borders and actors; Walther's (2009) typology examines spatial mobility; and Layton's (2007) description of Makola and Salaula marketplaces dissects the retail-end of ICBT. Our conceptualization of ICBT encapsulates its broader system's character. In the next section we provide background on ICBT before shifting to methods and conceptual development.

\section{Background}

The Organization for Economic Cooperation and Development (OECD) outlines three categories of informal cross border traders; (1) firms operating entirely outside the formal economy, (2) formally registered firms partially circumventing taxes and duties, and (3) formally registered firms fully evading paying their fair share of taxes and duties (Lesser and Moisé-Leeman 2009). A fourth grouping encompasses organizations/individuals facilitating trafficking and smuggling (see Titeca 2012). Exchanges comprising blatant illegal activity [i.e. (2), (3) and (4)] constitute criminal enterprise and thus do not qualify for "regular" informal cross border trade (Williams and Nadin 2010). We define informal cross border trade (ICBT) as market-based exchanges of legally produced/acquired goods, across national borders, which occur outside the remit of formal commercial activity. Exchanges fall outside the regulated space because (1) the traders involved may not be formally registered, and (2) the transactions may be sporadic and of such a low or hard to quantify commercial value, to draw sustained interest from regulators.

While there is no consensus on how to quantify ICBT, there is recognition it accounts for a substantial portion of economic activity (Koroma et al. 2017; Nkendah 2013; Ogalo 2010). By not recording all of this informal trade, official economic data ostensibly underestimate gross domestic product and trade statistics across several countries in Africa (Afrika and Ajumbo 2012). Thus, its study is fundamental for numerous developmental imperatives. As an expression of African Entrepreneurship, ICBT empowers traders by generating self-employment, and offers women flexibility and opportunity to participate in meaningful economic activity (Afrika and Ajumbo 2012; Dadzie, Akaah, and Dunson 1989). It helps fight unemployment and poverty - key obligations for Sub-Saharan Africa, where most countries are subsistence and bottom of the pyramid markets (African Development Bank 2015; Blankson, Cowan, and Darley 2018; Kotler, Roberto, and Leisner 2006; Lindeman 2014; Peterson and Zehra 2018; Prahalad and Hammond 2002). Thus, ICBT is relevant to the broader dialogue on inclusive economic development (Dadzie et al. 2013; Peterson and Zehra 2018; World Economic Forum 2018).

ICBT also constitutes a wicked problem (Churchman 1967; Rittel and Webber 1973). The wickedness arises primarily from social complexity - the diversity and interplay in the number of participants involved, and the fact that the problem is often a set of "interlocking issues and constraints" (Conklin 2006, p. 8). While policymakers across much of Sub-Saharan Africa view informal cross border traders as sole proprietorships and micro small-to-medium size enterprises (MSMEs); as the scale and scope of such trade grows, it decimates the base from which central authorities can collect crucial revenue. On one hand ICBT offers gainful employment, on the other it facilitates exploitation (especially of women) and intersects with various forms of (il)legality. We premise our study on Wooliscroft (2016) who advances the foremost goal of macromarketing is to confront wicked problems. To address ICBT's paradoxical nature outlined above, our study scrutinizes this phenomenon from a marketing systems lens (Layton and Grossbart 2006). How does one conceptualize ICBT from a macromarketing perspective? Is marketing systems design an option for informal markets? How does one design a marketing system inclusive of ICBT in order to reduce negative societal outcomes and maximize positive ones? How should policymakers approach this task?

To answer the preceding questions, the subsequent section introduces the conceptual frames and marketing systems' thinking to guide the research. We explore informal exchange networks and the importance of understanding ICBT from the perspective of marketing systems. This is followed by a methods section which highlights the literature review and justifies the adoption of "summarizing" and "delineating" techniques. We offer results of the review of 45 studies on ICBT and discuss them along seven themes. The thematic clusters are the bedrock of our conceptualization and depiction of ICBT as a substratum marketing system. Finally, we draw conclusions and chart directions for future research.

\section{Informal Exchange Systems and Formalization}

It is generally understood that the informal economy functions as an alternative, auxiliary, or complementary network of 
exchanges that stand in contrast to formal systems (Arellano 1994; Lomnitz 1988). Traditional economics sees informal exchange systems as the consequence of the formal economic sector's inability to deal effectively with its key functions (e.g. adaptive provisioning and flexible product assortments, creation of sufficient jobs, ease of doing business, and ensuring hassle-free entrepreneurship). Informal systems would exist as long as formal systems fail to produce and distribute assortments that society requires (Lomnitz 1988). Britan and Cohen (1980) argued that informal structures emanate from the deepening bureaucracy of formal arrangements. Since formal arrangements are rigid and inflexible, informal systems exploit such rigidities, while offering more deft and direct ways of solving exchange problems. In macromarketing, this view is echoed in Arellano's (1994) work that indicates that informal traders are efficient, hence this mode of economic exchanges would proliferate in low development countries due to a lack of formal control. Layton (2007) saw informal exchange systems as institutions that are formed parallel to formal marketing systems. He indicated that informal market exchanges provide assortments not offered by formal marketing systems (Layton 2007). Lomnitz (1988) extended this view, arguing that a close link exists between formal and informal exchange systems. Accordingly, informality is an adaptive mechanism of dealing with inadequacies of formal systems. Therefore, informal systems can be seen as an intrinsic element of formal systems.

Informal exchange networks provide an alternative view suggesting informal practices become manifest in light of formalizing interventions, because these practices epitomize primary economic activities entangled in society's social-cultural milieus (Gaughan and Ferman 1987). What appears "informal" is in fact a mode of societal provisioning operations underscored by socio-demographic and geo-political realities (Fisk 1967). Researchers (e.g. Gaughan and Ferman 1987) argued that informal exchanges, because they constitute the social matrix of culture-based provisioning, exist prior to formalization. The act of formalization brings selected aspects of commercial as well as cultural activities to the foreground in the shape of "formal" arrangements, while the rest of activities, despite constituting the original foundation of exchange, can be treated as "informal". Hence, the informal sector can be understood as the substratum of market activities anchoring formal systems, instead of an auxiliary structure.

The marketing-systems-as-the-public-good (MSPG) framework (Kadirov 2018) informs this alternative view of informal systems. The MSPG typology asserts that individuals derive value from participating in and contributing to just marketing systems; which is dissimilar from the value directly derived from the use/consumption of assortments. From this perspective, formal marketing systems operate as institutions constructed through formalization. Formalization occurs when some specific aspects of societal exchanges are separated from the complex environment as a formal domain, while some other aspects may appear as "informal" in reference to the formal. Formal marketing systems are not given, to the contrary, they are enabled through formalization reflected in property rights, rules-in-use, and design decisions (Ostrom 2005). The MSPG framework emphasizes the possibility of perceived injustice in formal systems, which may be manifested in the form of systemic barriers, limitations, inefficiencies, and irrationalities. Such manifestations can stimulate resource shifts from the formal sphere to the informal one, and vice versa.

Drawing on the MSPG framework, we contend that ICBT is the phenomenon that signifies an important substratum of marketing systems. Not only does it operate as a societal provisioning process, it also denotes a complex network of exchanges which are related to original societal provisioning structures prior to formal restrictions (e.g. colonization, borders, economic policy). Hence, ICBT can be seen as much more fundamental than current formal economic structures representing the outcome of (post)modernity and colonization. Based on these theoretical premises, we submit that ICBT operates as a dialectic mirror of formal exchange systems. It exists as it is (regardless whether it is seen as "informal" or "neutral"), while growing inadequacy of formal structures (i.e. mounting experiences of injustice in marketing systems) (Kadirov 2018), brings its size and scope to the foreground as a "problem" to be solved. Consequently, ICBT turns into a gauge of the effectiveness of formalizing practices in marketing systems. This is its substratum diagnosticity role - the more it is problematized, the more likely that marketing systems' formalization may have gone wrong. Ironically, a misguided marketing systems policy may incorrectly target ICBT (or informal markets in general), instead of targeting inadequate formalization processes of marketing systems.

\section{Methodology}

Our study is motivated by the lack of reviews and limited conceptual work on informal cross border trade. Kumar (2015), MacInnis (2011), and Yadav (2010) underscore that the decline of conceptual articles is a persistent issue across the marketing field. Yadav's (2010) work drew attention to the problem, while MacInnis's (2011) offered potential remedies. Conceptual articles are pivotal to scientific progress as they help advance a construct, domain or discipline (Crittenden and Peterson 2013; MacInnis 2011; Yadav 2010). Their value escalates when researchers examine pertinent problems (Kumar 2015; Layton and Grossbart 2006). To this end, we use a macromarketing perspective to cast informal cross border trade as a substratum marketing system. We employ "summarizing" and "delineating" techniques to attain our general conceptual goal of elucidating a domain (MacInnis 2011).

To paint a persuasive picture of ICBT (i.e. summarizing) and lay the foundation for our conceptual development, we utilize a method of literature review and provide a synthesis of past research. The literature review is guided by the following question; what are the defining features of informal cross border trade? Our review is systematic (see Briner, Denyer, and Rousseau 2009; Rousseau, Manning, and Denyer 2008; Tranfield, Denyer, and Smart 2003) in nature but not (necessarily) comprehensive in scope, in that the search is limited to two 
key terms "informal cross border trade" and "Africa". To the best of our knowledge, we are one of the first studies to attempt to integrate and synthesize the body of knowledge on ICBT. Using both broad (i.e. ABI Inform, JSTOR, and Science Direct) and publisher-related databases (i.e. Blackwell-Wiley, Elsevier, Emerald, Palgrave, Sage, Springer, and Taylor and Francis) our search included keywords, abstract, and full-text. After excluding newspaper and magazine articles, theses, books/ book chapters, reports of a general nature, and opinion pieces, our search harvested 45 peer-reviewed journal articles and authoritative reports published in English. Although our search was not restricted to any specific regions of Africa, all but one of the studies is drawn from outside the Sub-Saharan region. Appendix A provides a map of Africa, which highlights the expansive region in question. Aside from the island nations in the Indian Ocean (i.e. Comoros, Madagascar, Mauritius, Seychelles) nearly all Sub-Saharan African countries are covered/ referenced in our sample.

While it is common for systematic reviews to provide a bibliometric synopsis of the articles included, our review omits this step principally because the literature review itself is not the outcome but rather the tool which facilitates the conceptual development. Our approach is influenced by scholars (e.g. MacLure 2005; MacInnis 2011; Papadopoulos and Malhotra 2007; Paul and Mas 2019) who advocate the use of a literature review as a basis for conceptualization instead of only providing taxonomy on past research. Like several recent studies (e.g. Beninger and Shapiro 2019; McArthur, Weaven, and Dant 2016; Newman et al. 2014) that use literature reviews to theorize, we set aside the bibliometric profile and focus on assessing extant knowledge.

To code the data, we adopted a general inductive approach deriving from constant comparison analysis (Leech and Onwuegbuzie 2007; Thomas 2006). This approach was considered adequate since it allows researchers to consolidate data, underline links between research objective and data, and develop insights based on the underlying structure of the data (Thomas 2006, p. 238). We followed the five-step approach (i.e. initial reading of text data, identifying text chunks, labelling text chunks, reducing overlap and redundancy, and selecting thematic categories) suggested by Creswell (2002) and restated in Thomas (2006). Through this procedure, we identified seven thematic clusters - motive/origin, magnitude, assortment heterogeneity, entrepreneurialism, (il)legality, moral discourse, and (in)formalization. The number of clusters falls within the acceptable range (i.e. 3-8) for general inductive coding (see Creswell 2002; Thomas 2006). Appendix B provides an overview of the 45 studies reviewed, whereas Table 1 encapsulates knowledge content. The subsequent narrative synthesis refers to both the thematic clusters in Table 1 and key findings in Appendix B. Because the first stage of our theorization focuses on the review component, the clusters condense knowledge content on ICBT with no obvious attempts to articulate this in a macromarketing or marketing systems context. Only at the second stage of theorization (i.e. informal cross border trade as a substratum marketing system) do we use delineation to draw links between the thematic clusters and macromarketing/marketing systems.

\section{Thematic Clusters on Informal Cross Border Trade}

\section{Motives and Origins of ICBT}

Several scholars (see Akinboade 2005; Alusala 2010; Ama, Mangadi, and Ama 2014; Ellis and MacGaffey 1996; Flynn 1997; Koroma et al. 2017; Little 1992; Little, Tiki, and Debsu 2015; Manjokoto and Ranga 2017; Meagher 2003; Mohamadain and Ati 2015; Muzvidziwa 2001; Ndlela 2006; Nshimbi 2015; Ogalo 2010; Titeca and Kimanuka 2012; Yusuff 2014) have studied the origins (of) and motives (underpinning) informal cross border trade. There is a presumption that the emergent socio-economic reality of Africa, characterized by rural to urban migration, decline in agricultural production, the legacy of botched economic structural adjustment programmes, unemployment and underemployment, lack of opportunities for the youth, and porous borders explains modern ICBT (Akinboade 2005; Alusala 2010; Ama, Mangadi, and Ama 2014; Little, Tiki, and Debsu 2015; Manjokoto and Ranga 2017; Meagher 2003; Muzvidziwa 2001; Ndlela 2006; Ogalo 2010). Further, a neo-classic view on ICBT suggests it emanates from barriers Africa's harsh business environment spawns. The view is especially popular among multilateral lenders and supranational organizations including the African Development Bank (e.g. Afrika and Ajumbo 2012), Food and Agriculture Organization (e.g. Koroma et al. 2017) OECD (e.g. Lesser and Moisé-Leeman 2009), and the United States Agency for International Development (e.g. Blumberg, Malaba, and Meyers 2016) who point to high transactions costs, bureaucracy, corruption, lack of knowledge, restricted access to financing, and limited education and skills. The comparatively low ranking of African countries concerning ease of doing business, economic freedoms, corruption perception, and human development lends credence to this view. For instance, challenges in establishing and running a formal business (i.e. ease of doing business), explain the discrepancy between early stage entrepreneurial activities and actual start-ups in select African countries (see Herrington and Kelly 2012; Kahiya and Kennedy 2016).

Yet, ICBT predates modern Africa and traces to socio-ethnic affinities that have existed for centuries (Ellis and MacGaffey 1996; Koroma et al. 2017; Little 1992; Mohamadain and Ati 2015; Ogalo 2010). Murdock's (1967) ethnographic map of Africa, which demonstrates that the 54 countries constituting the continent today are 800-plus tribal/ethnic areas, comprising multiple layers of jurisdictional hierarchy, extending beyond the local village, provides an informative context. Economic exchange, predominantly in the form of barter trade helped to satisfy everyday needs and to cement those socio-ethnic affiliations. The "collectivist" cultural makeup of this region (see Hofstede 1980; Darley and Blankson 2008) was fundamental for weaving and embedding economic exchange in the social matrix (Hounhouigan et al. 2014; Layton 2011). As borders cropped up 
Table I. Thematic Clusters on Informal Cross Border Trade in Sub-Saharan Africa.

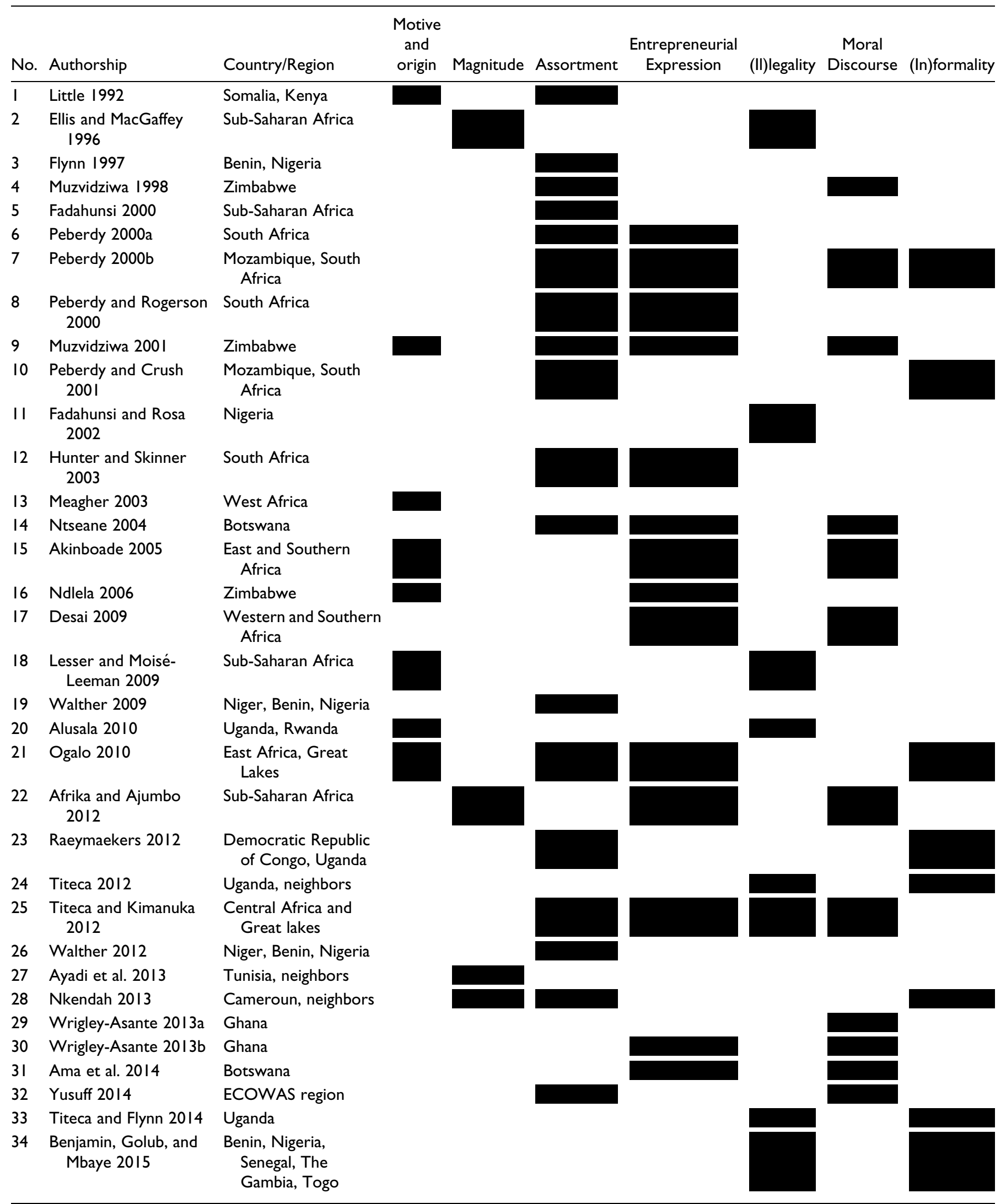


Table I. (continued)

\begin{tabular}{|c|c|c|c|c|c|c|c|c|c|}
\hline No. & Authorship & Country/Region & $\begin{array}{l}\text { Motive } \\
\text { and } \\
\text { origin }\end{array}$ & Magnitude & Assortment & $\begin{array}{l}\text { Entrepreneurial } \\
\text { Expression }\end{array}$ & (II)legality & $\begin{array}{c}\text { Moral } \\
\text { Discourse }\end{array}$ & (In)formality \\
\hline 36 & $\begin{array}{l}\text { Mohamadain and Ati } \\
2015\end{array}$ & Sudan & & & & & & & \\
\hline 38 & Shimuafeni 2015 & Namibia & & & & & & & \\
\hline 39 & $\begin{array}{l}\text { Blumberg, Malaba, and } \\
\text { Meyers } 2016\end{array}$ & Botswana, Malawi & & & & & & & \\
\hline 40 & Dobler 2016 & Africa & & & & & & & \\
\hline 41 & Koroma et al. 2017 & Sub-Saharan Africa & & & & & & & \\
\hline 44 & $\begin{array}{l}\text { Van den Boogaard, } \\
\text { Prichard, and Jibao } \\
2018\end{array}$ & Sierra-Leone & & & & & & & \\
\hline 45 & Nshimbi 2019 & $\begin{array}{c}\text { Zambia, Malawi, } \\
\text { Mozambique }\end{array}$ & & & & & & & \\
\hline
\end{tabular}

following colonization, ICBT became a symbol of both contempt and defiance, directed at colonial settlers for creating borders which some considered as artificial (Flynn 1997; Mohamadain and Ati 2015; Nshimbi 2015; Walther 2012). Modern Africa has retained these traditional ties between social and ethnic groups, and some communities view national borders as bridges instead of boundaries (Dobler 2016; Flynn 1997).

\section{Magnitude and Extent of ICBT}

A cluster of studies (e.g. Afrika and Ajumbo 2012; Ayadi et al. 2013; Ellis and MacGaffey 1996; Mohamadain and Ati 2015; Nkendah 2013; Shimuafeni 2015) attempts to estimate the magnitude of ICBT. Shimuafeni (2015) suggests $40 \%$ of Africa's GDP derives from the informal sector, of which ICBT is an integral component (Lesser and Moisé-Leeman 2009). ICBT accounts for nearly $70 \%$ of the employment in Sub-Saharan Africa, and 30 to $40 \%$ of intra-Africa trade in the Southern African Development Community (SADC) (Koroma et al. 2017). Within the SADC region, this translates to 100000 metric tonnes of maize and 41000 metric tonnes of other grains (e.g. rice and soya beans) per annum (Afrika and Ajumbo 2012; World Food Programme 2007). To the north, ICBT accounts for $50 \%$ of Tunisia's official bilateral trade with Libya, and approximately $10 \%$ with Algeria (Ayadi et al. 2013). Nearly a quarter of Sudanese households in the border regions of Gedarif and Kassala participate in ICBT (Mohamadain and Ati 2015).

Contrary to the traditional view, a strong formal sector may not guarantee the retrenchment of ICBT, and socioeconomically stable countries are more likely to be active exporters (Nkendah 2013; Shimuafeni 2015). For instance, $90 \%$ of the informal trade between Namibia and its neighbors is in the form of "exports" (Shimuafeni 2015). Likewise, Cameroon runs a "positive balance" of informal trade with contemporaries in the Economic and Monetary Community of Central Africa (CEMAC) (Nkendah 2013). It is essential to note most of these statistics pertain to trade in grain/food which is easier to quantify compared to the assortment of consumer durable and non-durable goods outlined below.

To appreciate the magnitude of ICBT, one has to acknowledge its broad, but not necessarily linear, contribution to economic activities in Africa. As the magnitude of economic activities considered formal increases, so does ICBT. It would be very simplistic to assume that the magnitudes of ICBT and formal systems are inversely related, at least so far as economic structures in Africa are concerned. For instance, Crush and Frayne (2011) note the informal food economy (which includes ICBT trade in food) is booming despite the rapid expansion of large supermarket chains (e.g. Pick $n$ Pay, Shoprite, and Woolworths) across much of Africa. Benjamin, Golub, and Mbaye (2015) observe that most ICBT transactions are re-exports, and this complicates the task of developing precise statistics given the possibility of double-counting. Some researchers (e.g. Ayadi et al. 2013; Lesser and Moisé-Leeman 2009; Ogalo 2010), therefore, conclude that the complete eradication of ICBT is not possible.

\section{Assortment Heterogeneity in ICBT}

Research (e.g. Ama, Mangadi, and Ama 2014; Dobler 2016; Flynn 1997; Hunter and Skinner 2003; Koroma et al. 2017; 
Little, Tiki, and Debsu 2015; Mohamadain and Ati 2015; Muzvidziwa 1998; Nkendah 2013; Nshimbi 2019; Ntseane 2004; Ogalo 2010; Peberdy 2000a, 2000b; Peberdy and Rogerson 2000; Raeymaekers 2012; Shimuafeni 2015; Titeca and Kimanuka 2012; Van den Boogaard, Prichard, and Jibao 2018; Walther 2009, 2012; Yusuff 2014) indicates ICBT is heterogeneous, the extent of which does not depend on the nature of the formal sector. It is not an appendage to formal structures in a sense that these activities target what is missed from formal marketing systems. The heterogeneity is largely linked to geographic factors, local skills, resources and endowments. For instance, the regions of East Africa trade mainly in foodstuff and livestock; the resource rich region of Central Africa exchanges minerals and jewellery, while the borders of Southern Africa see a fair share of clothing and handicrafts passing through (see Ama, Mangadi, and Ama 2014; Koroma et al. 2017; Little, Tiki, and Debsu 2015; Shimuafeni 2015; Titeca and Kimanuka 2012; Yusuff 2014). Nkendah (2013) suggests where higher levels of education are pervasive, ICBTs are more likely to perform multiple exchange functions and specialized roles in the value chain. Of these roles (i.e. exporter, intermediary, retailer, warehouser, and wholesaler) retailing is one of the most critical. This probably explains why most cities in SubSaharan Africa are dotted with Makolas and Salaulas - retail or consumer-facing informal marketplaces distributing wares from ICBT (Hunter and Skinner 2003; Layton 2007; Peberdy 2000a, 2000b; Peberdy and Rogerson 2000).

Studies (e.g. Ama, Mangadi, and Ama 2014; Mohamadain and Ati 2015; Nkendah 2013; Ntseane 2004) also show that spatial mobility and social networks play a pivotal role in shaping ICBT. Inhabitants of border towns are more likely to participate in ICBT than those from further afield (Ayadi et al. 2013; Flynn 1997; Mohamadain and Ati 2015; Nkendah 2013). The start-up capital maybe as little as $\$ 30.00$, sourced primarily from family and friends (Ama, Mangadi, and Ama 2014; Muzvidziwa 1998; Ntseane 2004). ICBT attracts unemployed and underemployed men and women aged 20 to 50, while foreign street traders (an offshoot of ICBT) comprise mostly single men in their 20's (Hunter and Skinner 2003; Muzvidziwa 1998, 2001; Peberdy 2000b; Peberdy and Rogerson 2000). Traders in their 20's are more likely to have secondary education than older peers (Ama, Mangadi, and Ama 2014; Hunter and Skinner 2003; Nkendah 2013; Ogalo 2010). They are omnipresent (in) but not limited to South Africa. For instance, Mohamadain and Ati (2015) observe that some traders operating in Sudan are "expatriates" of Ethiopian and Eritrean origin. The notion of foreign street traders offers glimpses into spatial mobility and transnational ICBT activities.

\section{ICBT as Entrepreneurial Expression}

A handful studies (Ama, Mangadi, and Ama 2014; Desai 2009; Koroma et al. 2017; Manjokoto and Ranga 2017; Muzvidziwa 2001; Ndlela 2006; Peberdy 2000b; Ogalo 2010; Titeca and Kimanuka 2012; Wrigley-Asante 2013b) suggest that informal cross border trade is a form of entrepreneurial expression (see Sridharan et al. 2014). This contrasts with a traditional view which depicts exchanges as opportunistic arbitrage that involves traders identifying gaps in the market or significant price-cost differentials across borders (Manjokoto and Ranga 2017; Titeca and Kimanuka 2012). It is true that price-cost differentials emanate from shortages/surpluses, and trade in grain surges in drought-stricken or conflict-ridden areas (Little, Tiki, and Debsu 2015; Titeca and Kimanuka 2012; World Food Programme 2007). However, what matters is the ability of traders to respond to these market shifts, which makes ICBT a more effective distribution channel than formal government mechanisms, especially in times of drought (Koroma et al. 2017; Tschirley and Jayne 2010; World Food Programme 2007). Other types of opportunities (e.g. trade in health and beauty supplies, car parts, and electronic products) bear the hallmarks of lifestyle-based or growth-focused entrepreneurship (Manjokoto and Ranga 2017; Muzvidziwa 2001; Ntseane 2004).

ICBT delivers myriad benefits for various actors including governments, traders, formally registered firms, and consumers (Afrika and Ajumbo 2012; Akinboade 2005; Koroma et al. 2017). Governments view informal cross border traders as subsistence entrepreneurs capable of attaining growth via "upgrading" (Babah Daouda, Ingenbleek, and van Trijp 2019). Consumers benefit from cost savings and assortment, while traders profit from low transaction costs. For instance, in Botswana, margins from ICBT are as high as $60 \%$ and on average, women informal cross border traders (WICBTs) earn more than five times the minimum wage (Ama, Mangadi, and Ama 2014). Proceeds from the exchanges have enabled multitudes of cross border traders across Africa to put food on the table, clothe their families, pay school fees for their children, and purchase household furniture and appliances (Ama, Mangadi, and Ama 2014; Koroma et al. 2017; Manjokoto and Ranga 2017; Muzvidziwa 2001; Ndlela 2006; Peberdy 2000b; Ogalo 2010; Titeca and Kimanuka 2012; Wrigley-Asante 2013b). Thus, ICBT exemplifies Africapitalism (see Muzanenhamo 2019) - a way of being and living for these communities.

\section{ICBT and (II)legality}

Virtually all forms of ICBT rob governments of two major sources of income; (1) internal revenue (i.e. income, sales and value added taxes) and (2) customs collections (i.e. import/ export duties, licences, taxes and other charges) (Afrika and Ajumbo 2012; Lesser and Moisé-Leeman 2009). This is particularly problematic in a region where governments could direct these proceeds toward human development priorities embracing, education, health, and poverty alleviation (see Blankson, Cowan, and Darley 2018; Kotler, Roberto, and Leisner 2006; Peterson and Zehra 2018). Furthermore, traders enjoy the same public goods (e.g. transportation and logistics infrastructure, and social services) as formal traders, without incurring commensurate costs (Nshimbi 2019). However, it can also be seen as a positive force in the context of the widespread incidence of ineffective/corrupt use of public resources including tax revenue. From this perspective, ICBT can potentially directly benefit impoverished communities. Moreover, it may 
possibly shift many households from being government support recipients to material independence.

Some researchers (Alusala 2010; Benjamin, Golub, and Mbaye 2015; Blumberg, Malaba, and Meyers 2016; Fadahunsi and Rosa 2002; Ellis and MacGaffey 1996; Titeca 2012; Titeca and Flynn 2014; Titeca and Kimanuka 2012) wade into the murky waters of what constitutes (il)legality. There is consensus (e.g. Benjamin, Golub, and Mbaye 2015; Blumberg, Malaba, and Meyers 2016; Little, Tiki, and Debsu 2015) that the difference between legal and illegal is more of a continuum than a dichotomy. In its purest form, ICBT involves the import and export of legally produced/acquired goods, by non-formally registered sole traders, through regular legal channels, with no attempt to evade international logistics gatekeepers such as customs and border control agents (Benjamin, Golub, and Mbaye 2015; Titeca and Kimanuka 2012). Beyond this point, most ICBT exchanges raise concern about (il)legality (Fadahunsi and Rosa 2002; Nshimbi 2019). To varying degrees, traders seek to bypass or dampen border-related costs, yet Fadahunsi and Rosa (2002) suggest this proclivity should not consign ICBT to the pile of illegal activity. Indeed, seeking to pay the lowest possible tariff is a legitimate and common practice among law-abiding formally registered multinational enterprises (MNEs) and small to medium size firms (SMEs). Complicating the distinction is the fact that although attempting to reduce import duties through under-invoicing is illegal in most jurisdictions, authorities in Togo and Benin encourage it, together with flexible application of tariff rates (Benjamin, Golub, and Mbaye 2015). Further, legality on "both sides of the ledger" cannot be guaranteed. For instance, transactions may consist of legal imports into countries with low tariffs, followed by informal exports (whose legality is open to scrutiny) to countries with higher tariffs (Benjamin, Golub, and Mbaye 2015). On the other end of the continuum, corruption and governance gaps leave ICBT vulnerable to flagrant transnational organized crime (Titeca 2018). Instigated by politicians and tycoons, the "weaponization" of ICBT eventuates when contraband encompassing ivory, precious metals, and weapons chokes the trade routes intended for legally produced/acquired goods (Alusala 2010; Blumberg, Malaba, and Meyers 2016; Ellis and MacGaffey 1996; Fadahunsi and Rosa 2002; Titeca 2012; Titeca and Flynn 2014). Most of the smuggling is conducted at blue borders (i.e. legitimate crossing points with all the accoutrements of modern international logistics), by elites from further afield, who display disdain for the border communities whose lives they disrupt (Dobler 2016). This smears legitimate traders with the same brush as smugglers.

\section{ICBT as Moral Discourse}

ICBT is not a neutral economic activity. It largely reflects the moral prerogatives and conventional norms of involved communities. For example, societal gender dynamics, often very brutal, are reflected in ICBT's structure. The majority of economies in Sub-Saharan Africa are dualistic in nature, comprising a male-dominated formal sector and a femaledominated informal/rural sector (Ndlela 2006). The African
Development Bank estimates that $60 \%$ of informal cross border traders are women (see Afrika and Ajumbo 2012). Women informal cross border traders (WICBTs) often have a low level of education, no bankable assets and little formal knowledge of how to run an enterprise. This is unsurprising given the nonnormative impetus for starting a business, which comprises dropping out of school, teen pregnancy, a failed marriage or coming from a dysfunctional home (Ntseane 2004; Peberdy 2000b; Titeca and Kimanuka 2012; Wrigley-Asante 2013a, 2013b). They operate in constant fear of threats (of), or actual physical, emotional and psychological harm (Akinboade 2005; Ama, Mangadi, and Ama 2014; Blumberg et al. 2016; Desai 2009; Manjokoto and Ranga 2017; Muzvidziwa 1998, 2001; Ntseane 2004; Titeca and Kimanuka 2012; Wrigley-Asante 2013a; Yusuff 2014). For instance, for some WICBTs, selecting a specific border crossing or transport provider amounts to "choosing a boyfriend" as touts (i.e. unauthorized valets and marshals at bus terminus, taxi ranks and some border crossings), conspiring with border control or transport providers, habitually demand sexual favors in exchange for commercial transactions (Blumberg, Malaba, and Meyers 2016; Titeca and Kimanuka 2012; Manjokoto and Ranga 2017; Wrigley-Asante 2013a; Yusuff 2014). Not only does this increase the risk of contracting and transmitting diseases, it leads to the stigmatization of some WICBTs as prostitutes (Blumberg, Malaba, and Meyers 2016; Manjokoto and Ranga 2017; Wrigley-Asante 2013a). Similar patterns of cultural complexity structure ICBT as a dominant moral discourse in society.

\section{(In)formalization}

Other scholars (e.g. Benjamin, Golub, and Mbaye 2015; Dobler 2016; Koroma et al. 2017; Little, Tiki, and Debsu 2015; Manjokoto and Ranga 2017; Nkendah 2013; Nshimbi 2015; Ogalo 2010; Peberdy 2000b; Raeymaekers 2012; Titeca 2012; Titeca and Flynn 2014; Van den Boogaard, Prichard, and Jibao 2018) have focused on disentangling formal and informal (market) dimensions of ICBT. Like the distinction between legal and illegal, extricating formal from informal markets is complex and confounding. ICBT thrives on hybrid governance mechanisms that juxtapose formal and informal markets (Titeca and Flynn 2014). These structures entail formalization of informal practices (e.g. holding something of value as bond or surety) and informalization of formal practices (e.g. negotiating a tariff rate) (Titeca and Flynn 2014). Van den Boogaard, Prichard, and Jibao's (2018) description of unofficial customs agents in Sierra-Leone (i.e. operating without official licenses and identification but lodging formal and legitimate declarations) embodies the juxtaposition. Ironically, ICBTs often form or join (formal) trade associations (Van den Boogaard, Prichard, and Jibao 2018; Wrigley-Asante 2013b). The advantages of this are dubious at best. For instance, traders who belong to trade organizations, face more harassment at the border (Van den Boogaard, Prichard, and Jibao 2018) and the trade associations are often irresolute (Wrigley-Asante 2013b). 
Table 2. Different Perspectives on Understanding Informal Cross Border Trade*.

\begin{tabular}{|c|c|c|}
\hline Manifestations & $\begin{array}{l}\text { ICBT as } \\
\text { Auxiliary System }\end{array}$ & $\begin{array}{l}\text { ICBT as } \\
\text { Substratum System }\end{array}$ \\
\hline $\begin{array}{l}\text { Motives and } \\
\text { Origins }\end{array}$ & $\begin{array}{l}\text { ICBT is the consequence of barriers to economic activity } \\
\text { in the formal sector. }\end{array}$ & $\begin{array}{l}\text { ICBT relates to the original bedrock of economic activities in } \\
\text { Africa. }\end{array}$ \\
\hline $\begin{array}{l}\text { Magnitude and } \\
\text { Extent }\end{array}$ & $\begin{array}{l}\text { The magnitude of ICBT and formal systems are linearly } \\
\text { inversely related. }\end{array}$ & $\begin{array}{l}\text { Growth in stable formal systems may enable increased ICBT, } \\
\text { and vice versa. }\end{array}$ \\
\hline $\begin{array}{l}\text { Assortment } \\
\text { Heterogeneity }\end{array}$ & $\begin{array}{l}\text { ICBT heterogeneity does not depend on the "misses" of } \\
\text { formal marketing systems. }\end{array}$ & $\begin{array}{l}\text { ICBT heterogeneity is largely associated with geographic } \\
\text { factors, available resources, skills, and the human factor. }\end{array}$ \\
\hline (II)legality & $\begin{array}{l}\text { ICBT comprises illegal activities (e.g. it drains public } \\
\text { resources). }\end{array}$ & $\begin{array}{l}\text { ICBT is a complex domain of hybrid activities (e.g. depending } \\
\text { on circumstances, it may save public resources). }\end{array}$ \\
\hline Moral Discourse & ICBT reflects neutral economic activities. & ICBT reflects moral dilemmas of society. \\
\hline (In)formalization & $\begin{array}{l}\text { Informal and formal are distinct domains that can be } \\
\text { analytically separated. }\end{array}$ & Informal and formal domains are inseparable. \\
\hline
\end{tabular}

*Delineation draws from Chen's (2007, p. 5) contrasting views on the informal economy

Well-educated informal cross border traders often hold jobs in the formal sector (Ama, Mangadi, and Ama 2014; Titeca and Kimanuka 2012; Yusuff 2014). Higher education levels among ICBTs allows them to straddle the formal/informal divide. Education gives them an appreciation of the broader formal market mechanisms (e.g. trade agreements) within which they should operate, but their everyday realities (e.g. low start capital, inability to handle large volumes, and recurrent challenges with working capital) accommodate informal transactions (Blumberg, Malaba, and Meyers 2016; Mohamadain and Ati 2015; Ogalo 2010). Merchandise acquired through formal markets can be on-sold via informal markets and vice versa (Benjamin, Golub, and Mbaye 2015; Koroma et al. 2017; Little, Tiki, and Debsu 2015; Manjokoto and Ranga 2017; Peberdy $2000 \mathrm{~b}$ ). While on-selling via formally registered enterprises may reduce margins for traders, collecting on outstanding payments is easier, compared to dealing directly with consumers. Thus selling to the final consumer via a formally registered retail outlet "cleanses" the goods of any stigma associated with ICBT. Just like the final consumer, these retail outlets profit from the attractive prices low transactions costs engender. Consumers get the best of both worlds; competitive prices plus legally binding assurances from registered retailers - which informal traders may be unwilling or unable to meet. At an aggregated level, the extent of interaction between formal and informal markets is hard to determine. For instance, Mawejje and Nampewo (2018) find that ICBT in agricultural products is not a long run driver of food prices in Uganda, while Raeymaekers (2012) suggests that this dualistic aspect creates a scenario where the formal could be subsumed (under) or supplanted by the informal.

\section{ICBT Framework and Discussion}

In developing the ICBT framework we follow MacInnis's (2011) suggestions on conceptual contributions. Our approach to "delineating" illustrates opposing observations on the same phenomenon such as; "what is simple is complex - what is complex is simple" or "what is macro is micro - what is micro is macro" (MacInnis 2011, p. 139). Knowledge from the seven thematic clusters in combination with Chen's $(2007$, p. 5) portrayal of contrasting views on the informal economy, allows us to identify and differentiate (i.e. delineate) two foremost perspectives on ICBT (see Table 2). These viewpoints are ICBT as an auxiliary marketing system (ICBT-AMS) and ICBT as a substratum marketing system (ICBT-SMS). The former is based on the traditional view of ICBT as a nuisance structure that augments mainstream marketing system structures and processes, while the latter views ICBT as a primary domain of market activities.

The ICBT-AMS perspective conceptually positions ICBT as an outcome of deficiencies in formal marketing systems reflected in difficulties, challenges, barriers, and bureaucratic hurdles which market actors face. The ICBT-SMS perspective, in contrast, sees ICBT as the original source of market activities which enables and supports formal structures, while recognizing that deficient formalization may revert some of market exchanges back to the original "pool". The proposed ICBTSMS framework in this paper depicts ICBT as a complex substratum marketing system. Due to its complexity, there is substantial interest from researchers, policymakers and supranational organizations to institute system design. As a prelude to our explanation of the ICBT-AMS perspective, we first outline failed attempts at system design and misconceptions about ICBT.

\section{ICBT and System Design}

Most of the interventions designed to eradicate or reduce the size of ICBT ensue from the view that it represents an auxiliary marketing system. This is a manifestation of a neoclassic perspective, which argues ICBT, like much of economic activity in the informal sector, is a drag on the efficiency and effectiveness of the formal economic system. The view presumes that 
the informal sector is marginally productive; informality is unrelated to the formal sector, entrepreneurs in the informal sector actively pursue (il)legality, and survival/necessity is the primary/sole motive behind the activities (Chen 2007). It disregards benefits of informalization (i.e. flexibility, low transaction costs, affordable assortments and rich heterogeneity for consumers and the formal sector, empowerment, and selfemployment) focusing instead on how to mitigate negative economic outcomes, especially plugging holes in a country's revenue collection efforts. This clarifies why countless supranational and non-governmental players (e.g. African Development Bank (AfDB), Food and Agriculture Organization (FAO), Organization for Economic Cooperation and Development (OECD), and United States Agency for International Development (USAID) dedicate substantial resources toward research positioned to eliminate "over-regulation" or barriers to formalization. They champion institutional reform under the pretext that a supportive or cooperative regulatory regime will enable traders to formalize. This, in turn, shrinks the number of participants in the auxiliary marketing system, as some will migrate to the formal sector. Efforts to encourage formalization via institutional reforms seldom generate the desired effect. For a large portion of traders, regardless of how much streamlining institutional reform entails, formalization will likely reduce flexibility, increase transaction costs, and eliminate margins.

Another neoclassic approach that the ICBT-AMS perspective promotes, tackles the "enforcement" dimension. Concerning the regulatory environment, Sub-Saharan Africa faces two extremes: on one hand are governance gaps or weaknesses in enforcement, on the other is unnecessary heavy-handedness and selective enforcement. Rogue touts, corrupt border control operatives, and unscrupulous traders (e.g. those operating in unregulated and often unsanitary spaces) continue to fester, taking advantage of lax enforcement. Meanwhile, unwarranted heavy-handedness occurs when regulators, in particular city councils and local enforcement, demolish marketspaces where informal traders operate. Raids frequently culminate in confiscation of wares, destruction of stalls, and unsightly, if not violent clashes. This harsh intervention often borders on criminalization of the informal sector. Selective enforcement implies regulators will clamp down on one form of transgression while turning a blind eye on another. Traders toiling to make ends meet may be the subject of scrutiny for failure to declare the full value of their goods, while political elites escape "unchecked". As alluded to in the literature review, "enforcement" alone is a dead-end given the state's role in the "normalization and quasi-institutionalization of these practices" (Van den Boogaard, Prichard, and Jibao 2018, p. 8).

The weaknesses of the enforcement approach poke holes in the validity and viability of the ICBT-AMS perspective. It is reactive, since it attempts to address undesired outcomes but does not constitute a viable method for system redesign. Thus far, we have advanced that attempts to influence ICBT using traditional interventions, have had limited success. To further this point, we illustrate how the ICBT-AMS perspective perpetuates common misconceptions about ICBT.

\section{ICBT and Misconceptions}

Our discussion of outcome-based attempts at system design shows that current interventions pivot toward eliminating undesirable outcomes. They ignore positive outcomes, much less other components or attributes of the system. To generate rich insight, we address some common presumptions vis-à-vis factors sustaining ICBT as a marketing system. These misconceptions emanate from the neoclassic-inspired perspective on which the ICBT-AMS framework rests. We illustrate, instead, how trends in Sub-Saharan Africa are challenging these presumptions.

The persistence of ICBT defies some assumptions underpinning ICBT-AMS. We focus on three such aspects - rural to urban migration, poverty, and unemployment. Appendix C provides anecdotal statistics to back our argument. For instance, the presumption that within country rural to urban migration precedes ICBT does not align with published statistics on trends in migration. Food and Agriculture Organization (FAO) illustrates that in recent years, within country rural to urban migration is just one component of a multifarious network of migration flows (Mercandalli and Losch 2017 , p. 23). Focusing solely on the rural to urban dyad disregards the fact that migrants from rural border communities often move to, or trade directly with, urban communities in other countries without ever engaging with urban communities in their native countries. This is particularly true of migrants from other African countries, who settle in or trade with communities in South Africa. In this instance, and many others, cross border trade is unrelated to within country rural to urban migration.

Another major thrust of the ICBT-AMS view argues ICBT feeds off high rates of unemployment or low labor participation rates, especially in urban areas. This contention has validity prima facie, but hard data on employment trends are somewhat at odds with this view. World Bank's data (see Appendix C) shows unemployment has tracked around 7.5\% over the past two decades. Others may go as far as arguing unemployment has steadily decreased. The point is, hard data do not substantiate that unemployment sustains ICBT as a marketing system.

Another generalization advances ICBT is an artefact of poverty. The deeper poverty cuts, the higher the likelihood citizens look to ICBT as a means of sustenance. Again, in principle, we take no issue with the postulation, but we point out that this is a partial explanation of ICBT. The poverty headcount (based on U\$D 1.90/day criterion) has gradually dissipated since the mid1990s (see Appendix C). Today, roughly 40\% of Sub-Saharan Africa lives in extreme poverty compared to nearly $60 \%$ in the early 1990's. The anecdote holds regardless of which threshold (i.e. $\$ 3.20 / \$ 5.50)$ is used. ICBT continues to blossom as a marketing system, despite a gradual erosion of the system environment (abject poverty, rural to urban migration and unemployment) on which it supposedly rests. We argue its persistence is incompatible with the attributes (of) and assumptions (about) auxiliary marketing systems. 


\section{Moving toward the ICBT-SMS Perspective}

The foregoing discussion provides an interesting example of Lomnitz's (1988) thesis, which argues laws of economic exchange fail to capture the undercurrents of informal markets. The limited success of myriad attempts to formalize ICBT stand out as an anomaly, so too does the fact that the system appears to flourish even when the system environment (e.g. trends in migration, unemployment, and poverty) is not necessarily conducive. Extending Lomnitz (1988) to our research, we argue that the country's socio-historical paths of dealing with provisioning challenges can explain the extent of ICBT. In the Sub-Saharan context, the dysfunction frequently goes to the formal economic system. A number of national and regional economic systems across Sub-Saharan Africa, be they centrally planned, free market or mixed, fail to adequately deliver on essential assortments. Of particular concern is the susceptibility of such systems to droughts and famine, which often would not survive without the support from ICBT in food or even livestock. Equally, the inability of private sector subsystems to offer affordable electronics, electrical and other consumer durables leave gaps open in the market, which ICBT plugs. Thus, it is not so much that poverty, unemployment and migration are driving participants into ICBT, as it is the fact that entrepreneurial individuals are simply acting business as usual. Hence, to solve many societal issues, correct forms of ICBT must be nurtured, rather than eradicated.

\section{Conclusions and Implications}

To elucidate the ICBT-SMS framework, and draw conclusions and implications, we revisit the guiding questions in the introduction and background - How does one conceptualize ICBT from a macromarketing perspective? Is marketing systems design an option for informal markets? How does one design a marketing system inclusive of ICBT in order to reduce negative societal outcomes and maximize positive ones? How should policymakers approach this task? One can conceptualize ICBT from a macromarketing perspective by blending the Marketing Systems as the Public Good (MSPG) (see Kadirov 2018) view and knowledge on informal markets (e.g. Arellano 1994; Chen 2007). In line with the new perspective on informal markets (see Chen 2007), we contend ICBT is a societal mode of operation, which constitutes the social fabric of culturebased provisioning. From a MSPG (see Kadirov 2018) standpoint, ICBT symbolizes an alternative sphere toward which market actors would strive if they perceive formal systems becoming unjust. Hence, any attempts to reduce it via formalization or enforcement, rips the very social fabric on which culture-based provisioning is stitched.

System design is an option for informal markets such as informal cross border trade. Layton (2007) indicates system design is vital for enhancing the value deriving from marketing systems and also reducing the vulnerabilities. The aforementioned paradoxical nature of ICBT entails it generates considerable benefits, while creating bothersome concerns. It manifests a substratum which is grounded in an expression of African entrepreneurship, creates a source of income, and empowers individuals and communities by giving them a chance to earn a living, honest or otherwise. Similarly, consumers benefit from the availability of an assortment of inexpensive products. However, our dissection of the vulnerabilities associated with ICBT, indicate the significance of systems design not only to eliminate the negative outcomes but also to manage the extent/scope. Acknowledging the potential role of system design is the easy path - far more daunting is the task of effecting it.

In designing a marketing system inclusive of ICBT, policymakers should appreciate its diagnosticity role. We have argued that the enforcement approach to system change is futile, as it treats ICBT as an auxiliary instead of the very foundation anchoring formal systems. This is where the substratum diagnosticity role of ICBT becomes critical. As a dialectical mirror, ICBT reflects inadequacies and inefficiencies in formal marketing systems. The growth in its size and scope, seen in recent years, brings to the foreground the efficacy of formal marketing systems. Thus, market policies targeting ICBT, specifically, miss the mark as the dialectical mirror projects issues with inadequate formal marketing systems. From a MSPG perspective, policymakers should direct their efforts toward creating better formalization processes which reconstruct current ICBT structures in the shape of a public good that benefits communities as well as the trade itself.

Policymakers should approach this by acknowledging that ICBT is not a set of nuisance phenomena, and that institutional reforms targeted at improving the entrepreneurial ecosystem (i.e. system environment) may be ineffective. Such reforms may, unwittingly, alter the system environment to such a point that customarily profitable ICBT may no longer be lucrative. In most jurisdictions, formalization has a toll on critical aspects such as time, resources required, independence, and flexibility. What is lost on most regulators is that ICBT, by its very nature, exemplifies a comprehensive form of streamlining. Our conclusion substantiates Arellano (1994) and Britan and Cohen (1980) who suggest that, notwithstanding the excesses covered in earlier discussions, informal systems are inherently efficient. For instance, Fadahunsi and Rosa (2002) note informal cross border traders have extensive flexibility in determining product/market configurations because they are not shackled by long term investments in property, plant, equipment, or labor. This places cross border traders "closer to the pulse of the market" than ventures operating in the formal space (Fadahunsi and Rosa 2002 , p. 401). Thus our ICBT as a substratum marketing system framework views the phenomenon as intentional African entrepreneurship, which serves both informal and formal traders, creates benefits for individuals and communities, and operates in a manner which challenges traditional neoclassic perspectives.

\section{Final Remarks and Directions for Future Research}

We drew evidence from a literature review and augmented this with systems-based conceptualization. The MSPG 
framework (Kadirov 2018), in combination with various models on informal markets (e.g. Arellano 1994; Chen 2007; Lomnitz 1988), provided the theoretical grounding for the discussion. ICBT persists in a manner at odds with falling rates of poverty, unemployment, and rural to urban migration. It is an efficient societal version of culture-based provisioning, and a dialectical tool that policymakers should use to gauge the effectiveness of formal market systems. What we call ICBT today represents traditional societal exchanges, which have, and will continue to survive political boundaries and formal market systems. Thus ICBT has a role (albeit a somewhat controversial one) to play toward inclusive economic development in Sub-Saharan Africa.

There are several promising directions in which future scholars could take this study. Measuring the magnitude and extent of ICBT remains a pressing challenge. The perennially clandestine nature in which ICBT operates creates barriers to the collection of accurate and verifiable data. It is unsurprising that attempts to correlate data on ICBT to common economic indicators provides inconclusive results. We call on researchers in other disciplines to explore ways of collecting data or developing algorithms to capture the magnitude and extent of ICBT. Only with quality statistics can we develop a better understanding of the socio-economic impact of ICBT.

If ICBT symbolizes Africa's invisible integration, what can policymakers do to enhance visibility while reducing the vulnerabilities? Increasing the visibility will showcase the wickedness - everyday entrepreneurship juxtaposed with the uncomfortable moral discourse detailed in this paper. Will the content and tone of this moral discourse change as societal values and attitudes evolve? Regardless of its economic outcomes, policymakers have an obligation to help create a safe environment for all actors. Regrettably, in most instances, state actors are complicit (in enabling) or ambivalent (toward eradicating) corruption, harassment, sexual abuse, smuggling among other vices. An immediate test to our conceptualization is the recently announced (ICBT-AMS inspired) Africa Continental Free Trade Agreement (AfCFA), developed to formalize and increase intraregional trade. Our ICBT-SMS framework envisages informal cross border trade will continue to flourish even in the era of this trade deal. We encourage future studies to test this prediction.

As stated in the introduction, informal cross border trade is not a preserve for Sub-Saharan Africa. Indeed, we see parallels between our study and Sridharan et al.'s (2014) description of Transformative Subsistence Entrepreneurship (TSE) in India. Thus future studies can test whether our proposed framework and its rationale hold in other settings such as Eastern Europe or South-east Asia. Beyond developing and transitioning economies, it is likely that informal cross border trade shares links with the notion of a "side hustle" (i.e. creative way of earning extra dollars) popular in other countries. Of particular note are daigou retail channels in China and the online import/ export of goods via platforms such as Alibaba, Amazon and eBay, by individuals operating as unregistered sole traders. What parallels exist between "side hustle" and ICBT? What can the two systems learn from each other?

Our conceptual paper is not without its limitations. The pan-disciplinary nature of ICBT and the lack of a prior review to serve as a point of reference, means we may have missed other potentially useful studies. The analysis and synthesis derived from the rudimentary techniques of "summarizing" and "delineating", and our proposed typology did not go as far as offering guidelines for testing in an empirical setting. Nonetheless, we have proffered the informal cross border trade as a substratum marketing system (ICBT-SMS) framework, which is generalizable to Sub-Saharan Africa and perhaps beyond. 


\section{Appendix A. Map of Africa with Sub-Saharan Region Indicated in Color}

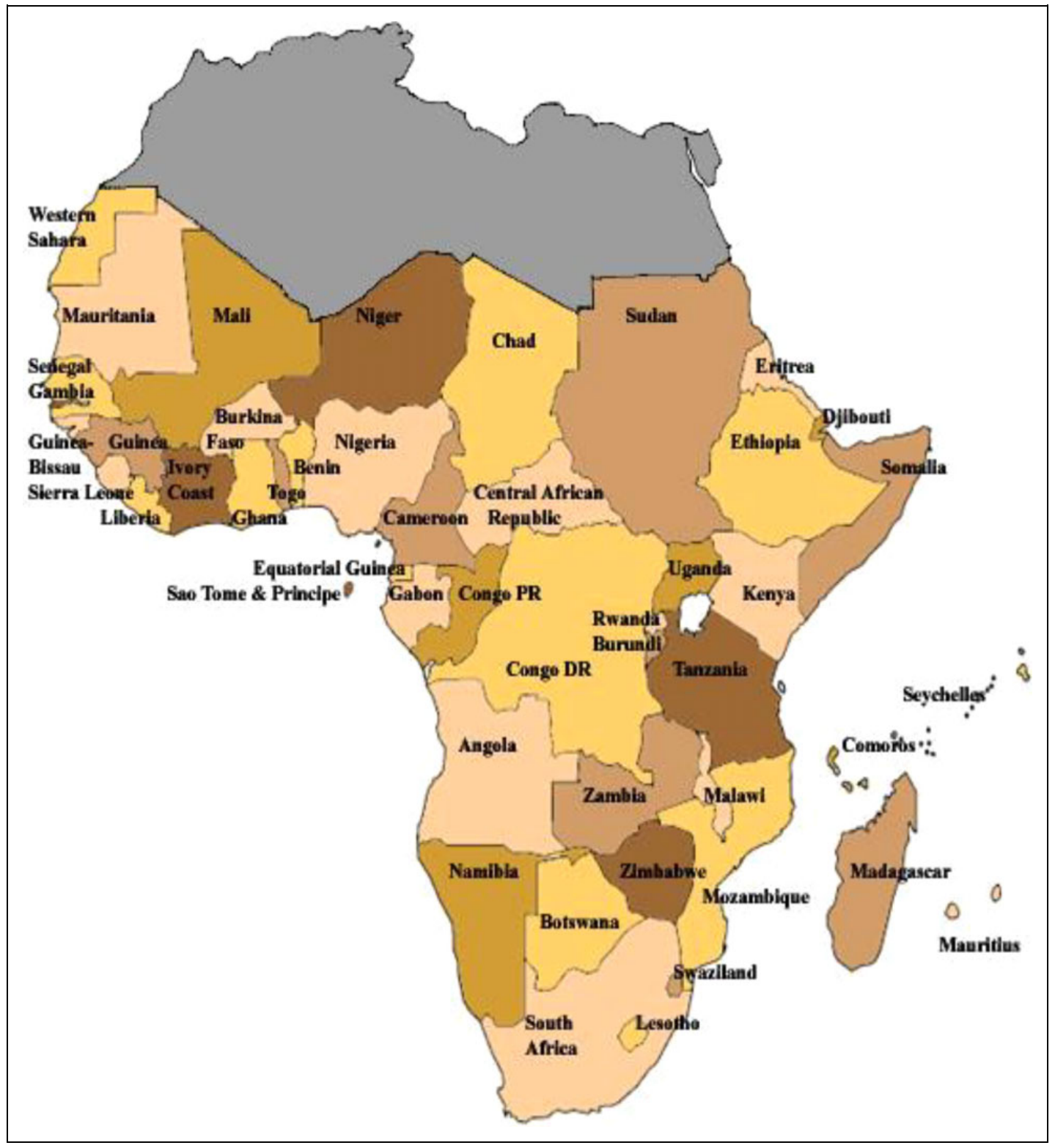

https://upload.wikimedia.org/wikipedia/commons/b/b9/Subsaharanafrica.jpg

\section{Appendix B. Overview of Studies on Informal Cross Border Trade (ICBT) in Sub-Saharan Africa}

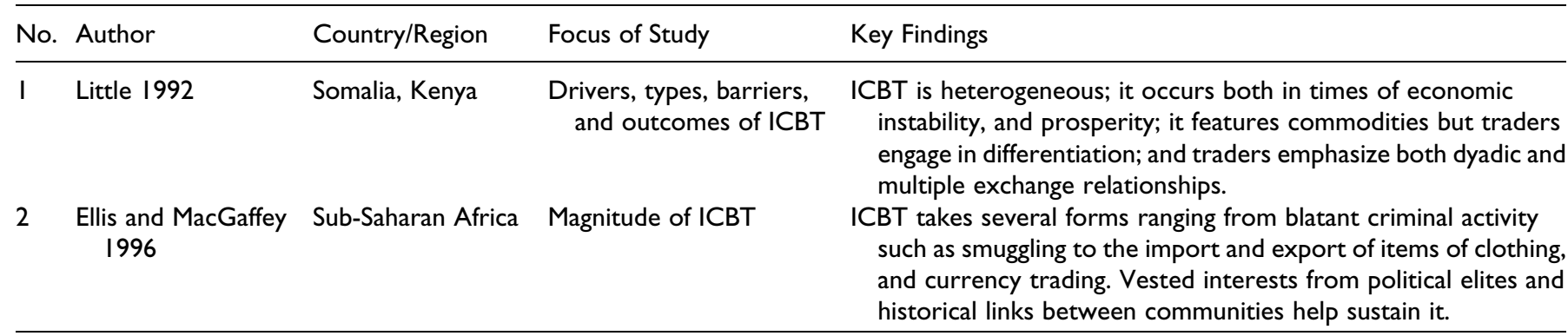


Appendix B (continued)

\begin{tabular}{llll}
\hline No. & Author & Country/Region & Focus of Study \\
\hline 3 & Flynn 1997 & Benin, Nigeria & $\begin{array}{c}\text { Territorial claims and } \\
\text { border identity }\end{array}$ \\
4 & Muzvidziwa 1998 & Zimbabwe & $\begin{array}{c}\text { Gender and poverty in } \\
\text { ICBT }\end{array}$
\end{tabular}

Key Findings

Border communities find a voice and an identity through the commercial activity conducted across the border. They see the border more as a bridge linking communities than a barrier separating them.

Most traders are aged 20 to 47 and their motive is to supplement household income. Start-up capital is sourced principally from informal personal networks. Traders are often vilified by the media as "greedy" - "unpatriotic" - "economic saboteurs". Women informal cross border traders (WICBT) often face allegations of witchcraft and promiscuity. 5 Fadahunsi 2000 Sub-Saharan Africa $\begin{gathered}\text { Methodological issues in } \\ \text { studying ICBT }\end{gathered}$

Notwithstanding their capacity to foster empirical generalizations, quantitative research designs may be unsuitable for studying informal entrepreneurship in Africa. This is mainly due to their inability to capture nuance and myriad factors at play. Ethnographic approaches, especially participant observation, remain useful.

6 Peberdy 2000a South Africa

Non-South Africans' participation in street trade

7 Peberdy $2000 \mathrm{~b}$

8

Peberdy and South Africa Rogerson 2000

Mozambique, South Linkage between formal Africa and informal activities

A portion of street traders in South Africa are ICBTs, in that they bring product from their home countries into South Africa, sell it in open stalls, and use the proceeds to export product out of South Africa into their home markets.

ICBT provides primary or supplementary income for food, shelter, clothing and education. Informal and formal trade intersect. For instance, products sourced via ICBT can be onsold to consumers via formal retail outlets.

Foreign street traders in South Africa either serve as the retail-end of ICBT or may be ICBTs seeking to control or manage the entire channel. Non-South African street traders face challenges ranging from harassment by law enforcement to violent xenophobic attacks.

ICBT gives traders independence, a stronger sense of identity, and fortitude. It creates a new dispensation which does not recognize tribal and linguistic differences and allows traders to

showcase creativity, ingenuity, and entrepreneurial acumen.

10 Peberdy and Crush 2001

Mozambique, South Economic zones and ICBT Africa

II Fadahunsi and Rosa Nigeria 2002

Gender and poverty in ICBT

Maputo Corridor Spatial Development Initiative (SDI) - a

programme set to foster economic potential/development in a post-apartheid era, generally overlooks ICBT. Not only is ICBT peripheral in policy development, traders are not fully aware of potentially relevant polices, which undermines the impact of programmes such as SDI.

Intrusion of contraband in Most informal cross border trade intersects with, or embodies ICBT some element of (il)legality. The (il)legality differs from the neoclassic Western view in that ICBT does not thrive off trading in illegal goods; it devotes entrepreneurial energy towards circumventing cumbersome rules or harassment at the hands of corrupt enforcement officials.

12 Hunter and Skinner South Africa 2003

Non-South Africans' participation in street trade

Foreign street traders (i.e. operating at the retail-end of ICBT) are generally more educated than their South African counterparts. They encounter myriad obstacles like lack of recognition, lack of proper infrastructure, police harassment, general abuse, and in the worst case, violent xenophobic attacks.

13 Meagher $2003 \quad$ West Africa
The wave of economic structural adjustment programmes and other neo-classic reforms were meant to increase formalization of economic activities - thus reduce ICBT. In West Africa, the contrary has occurred in that ICBT has continued unabated in the face of a bigger push toward neoliberal economics and formalization. 
Appendix B (continued)

\begin{tabular}{llll}
\hline No. & Author & Country/Region & Focus of Study \\
\hline I4 & Ntseane 2004 & Botswana & $\begin{array}{c}\text { Gender and poverty in } \\
\text { ICBT }\end{array}$
\end{tabular}

Key Findings

15 Akinboade 2005

East and Southern Africa

16 Ndlela 2006

Zimbabwe

17 Desai 2009

18 Lesser and MoiséLeeman 2009

19

Walther 2009

20

Alusala 2010

21 Ogalo 2010

22

Afrika and Ajumbo Sub-Saharan Africa 2012

23

Raeymaekers 2012

24 Titeca 2012

25 Titeca and Kimanuka 2012
Democratic Republic of Congo, Uganda

\section{Western and Southern Africa}

Sub-Saharan Africa

Niger, Benin, Nigeria

Uganda, Rwanda

East Africa, Great Lakes

Magnitude, barriers, and policy interventions

Interaction between

states and borderlands

Drivers, types, barriers, and outcomes of ICBT

Uganda, neighbors

Intrusion of contraband in ICBT

Central Africa and Great lakes ICBT trusion of contraband in

Botswanan businesswomen share common backgrounds including dropping out of school, teen pregnancy, a failed marriage or coming from a dysfunctional home. Personal networks are the primary source of initial capital. Societal expectations and gender-role stereotyping present constant problems.

Driven into poverty by lack of education, limited opportunities for formal employment, lack of capital, and general marginalization, ICBT presents a lucrative but hazardous choice for WICBTs.

The formal sector in Zimbabwe has never accounted for much more than $40 \%$ of all economic activities. Despite being overlooked in policy discourse, ICBT continues to provide a viable means of livelihood for many citizens.

ICBT empowers women with a voice and an opportunity to participate in the global economy. The prevalence of ICBT, the benefits it delivers, and challenges it poses, should force us to rethink our understanding of global trade.

Most ICBT involves staple food commodities (e.g. rice and maize) and basic consumer goods (i.e. apparel and electronic appliances). The extent of informality varies depending on how transactions are processed at the border, and whether any part of the operation involves formally registered entities/ participants.

Traditionally, economic activity in the Sahel originated from spatial mobility - the constant movement of actors within a space. While colonization and the subsequent ill-fated postindependence economic reforms attempted to rigidify the economic system, spatial mobility persists, supported in part by patterns of patronage and clientilism.

The porosity of borders not only facilitates informal cross border trade (invisible economic integration), it creates security risks ensuing principally from small arms trade.

While ICBT has always been a preserve for individuals with low levels of education, increasingly, well-educated unemployed youths are looking to it as a last resort. Most transactions involve staple foods and low quality consumer goods. Most traders are aware of formal trade arrangements like the Customs Union in the East African Community (EAC).

Poor regulatory settings (e.g. corruption, lack of finance, limited education, and lax border enforcement) characterize ICBT. Consumers are the biggest beneficiaries from ICBT, whereas governments miss out on revenue collection.

Informal cross border trade typifies an encroachment of informal activities into the formal space. In some instances this represents somewhat of a role reversal with tribal/ethnic groups, displaced and disenfranchised by colonization, reclaiming their territory or border back.

Tycoons, businessmen, and politically connected figures "weaponize" ICBT by using it for purposes of smuggling. On one hand tycoons attempt to play within the rules and interact with the formal sector, on the other they often seek and receive protection from regulators.

Gender and challenges in Trading food surpluses often leads to better food security.
"Arbitrage" opportunities arising from differences in levels of subsidies and varying tax regimes help sustain ICBT. 
Appendix B (continued)

\begin{tabular}{llll}
\hline No. & Author & Country/Region & Focus of Study \\
\hline 26 & Walther 2012 & $\begin{array}{c}\text { Niger, Benin, } \\
\text { Nigeria }\end{array}$ & $\begin{array}{c}\text { Origin, trade flows, and } \\
\text { types of goods traded }\end{array}$
\end{tabular}

Key Findings

27 Ayadi et al. 2013 Tunisia, neighbors Magnitude of ICBT

Most of the traders in the Great Lakes represent predominantly two ethnic groups. Their roles (on both sides of the border) cover imports/exports and countless goods/services such as retailing, food, electronics, and spare parts.

CBT accounts for more than $50 \%$ of Tunisia's official bilateral trade with Libya, and roughly 10\% with Algeria. Exact statistics are inherently problematic to compute given the surreptitious nature ICBT operates.

28 Nkendah $2013 \quad$ Cameroun, Magnitude of ICBT neighbors

There is evidence of role specialization with traders identifying as one of the following; warehouser, retailer, exporter, wholesaler or intermediary. Functions include exchange (i.e. purchase/ sale), physical (i.e. transportation), and information.

29 Wrigley-Asante Ghana $2013 a$

Gender and challenges in ICBT

30 Wrigley-Asante

Ghana $2013 b$

Gender, poverty, and well-being in ICBT

3I Ama et al. 2014 Botswana

Gender and challenges in ICBT

32 Yussuf 2014

ECOWAS region

Gender and challenges in ICBT

Occupational hazards WICBTs face comprise exposure to criminal elements and diseases, lack of sleep, dealing with defaulting customers, and psychosocial stress. While WICBTs are generally knowledgeable about sexual health, there is no formal educational programme which caters to their situation.

Most WICBTs are introduced to the trade by a member of their immediate social group (e.g. sibling or friend). Although travelling long distances, dealing with perishable products, harassment at the border, and unwanted sexual advances present persistent challenges, they still view ICBT as a way of earning an income to support their households.

Nearly two-thirds of the WICBTs are single (i.e. never married), divorced, widowed or cohabiting. The majority are aged between $3 \mathrm{I}$ and 40 and roughly three quarters have been in the trade for less than five years. The foremost reasons for engaging in ICBT are creating a form of business/employment and a source of supplementary income.

Proximity to the border and supplementing household income motivate WICBTs. Challenges encompass fluctuating exchange rates, harassment, theft and robberies, unwanted sexual advances, and exposure to HIV/Aids.

33 Titeca and Flynn Uganda 2014

Governance gaps and meaning of il(legality)

Hybrid governance mechanisms, in which neither state nor private, formal nor informal participants wield a monopoly, sustain ICBT. The notion of legal and illegal is fuzzy and peripheral to the structure and functions of these hybrid governance mechanisms.

34 Benjamin et al. 2015 Benin, Nigeria, Senegal, The Gambia, Togo

35 Little et al. 2015

Ethiopia, Kenya, Somalia

36

Mohamadain and Sudan Ati 2015

37 Nshimbi 2015
Overlap between formal and informal activities

Most transactions are re-exports in that goods are brought legally into countries with low import barriers (e.g., Benin, The Gambia, and Togo) by formally registered businesses, and exported through myriad informal channels to countries with higher import barriers (e.g., Nigeria and Senegal).

Overlap between formal and informal activities

The lack of border posts enables trade in livestock. Even where border posts exist, inconsistency and ambiguity in the application of policies blurs the boundaries between formal and informal markets, and legal and illegal transactions.

Characteristics of ICBT Some ICBTs operating in Sudan are 'expatriates' of Ethiopian and Eritrean origin. Historical ethnic/tribal links help foster informal cross border cooperation. Most participants have a low level of education and those with secondary and/or tertiary education straddle formal and informal markets.

The majority of traders from these three countries identify with one of two tribes; Chewa and Ngoni. Because sociocultural links (i.e. language, culture, tribe, and ethnicity) predate colonization and are much stronger than national borders, it is imperative to recognize their impact. 
Appendix B (continued)

\begin{tabular}{llll}
\hline No. & Author & Country/Region & Focus of Study \\
\hline 38 & Shimuafeni 20I5 & Namibia & Magnitude of ICBT \\
& & \\
39 & $\begin{array}{c}\text { Blumberg et al. } \\
2016\end{array}$ & Botswana, Malawi & $\begin{array}{c}\text { Gender and challenges in } \\
\text { ICBT }\end{array}$
\end{tabular}

Key Findings

Exports account for nearly $90 \%$ of Namibia's ICBT. Aside from tobacco and alcoholic beverages, vegetables, and jewellery, Namibia is a net exporter of most consumer goods (i.e. food and apparel). These exports go to Angola, South Africa, and Zambia. Angola is the leading destination for both exports and imports.

WICBTs constitute $70-80 \%$ of all traders in Southern Africa. They exchange mostly legally produced/acquired merchandise, although some transactions may involve contraband especially precious metal. Lack of information, lack of credit/finance, corruption, sexual exploitation, and gender-based violence besmirch ICBT. Some countries (e.g. Zambia and Zimbabwe) are trialing one stop border post systems to eliminate bottlenecks and increase efficiencies at border crossings.

40 Dobler $2016 \quad$ Africa

Types/roles of borders and border actors

Green borders refer to paths in the bush or undesignated border crossings; grey borders are small under-resourced border posts that serve what might appear to be an honorary yet instrumental role; blue borders have all the accoutrements of formal trading spaces including logistics infrastructure and service providers.

4I Koroma et al. 2017 Sub-Saharan Africa Governance and regulation in ICBT

Zimbabwe Ranga 2017

43

Mawejje and Uganda
Nampewo 2018

44 Van den Boogaard et al. 2018
Gender and challenges in ICBT Effect of ICBT on food
prices

Drivers, magnitude, and attributes of ICBT

\footnotetext{
Governance and regulation in ICBT
}

ICBT provides nearly $70 \%$ of employment in Sub-Saharan Africa, and within the Southern African Development Community (SADC), it accounts for nearly U\$DI8 billion's worth (or 30$40 \%$ ) of intra-regional trade. WICBTs constitute $70 \%$ of all traders. To get the most out of ICBT, policymakers should encourage formalization through streamlining regulations, tackling corruption, and creating informational and financing resources.

The majority of WICBTs are single or widowed, and only half have secondary education. Increasingly, WICBTs are dealing in auto parts, taking advantage of the influx across much of Africa, of second hand cars from Japan. They sleep in the open (stalls, bus and rail stations) placing themselves at risk of rape and robbery, and the time spent away puts a strain on households particularly those with young children.

ICBT in agricultural products is not a long run driver of food prices in Uganda. However, there is unidirectional causality between agricultural ICBT and agricultural output.

Formal and informal markets are often inseparable. For instance, "informal" customs agents (i.e. operating without official licences and identification) often lodge legitimate formal declarations for customers. The customs duties comprise a cocktail of official (formal) and unofficial (informal) payments. On one hand traders can pay formal customs duties, on the other they can negotiate preferred customs duties at the border.

Some ICBTs confess to resorting to some illegal activity including under-invoicing, concealment/smuggling, and making false declarations. They attribute this to time constraints, and the impracticality of following proper procedure. ICBTs routinely access social (i.e. health and educational) services across the border.
Zambia, Malawi, Mozambique 


\section{Appendix C. Trends Inconsistent with Neoclassic ICBT-AMS View}

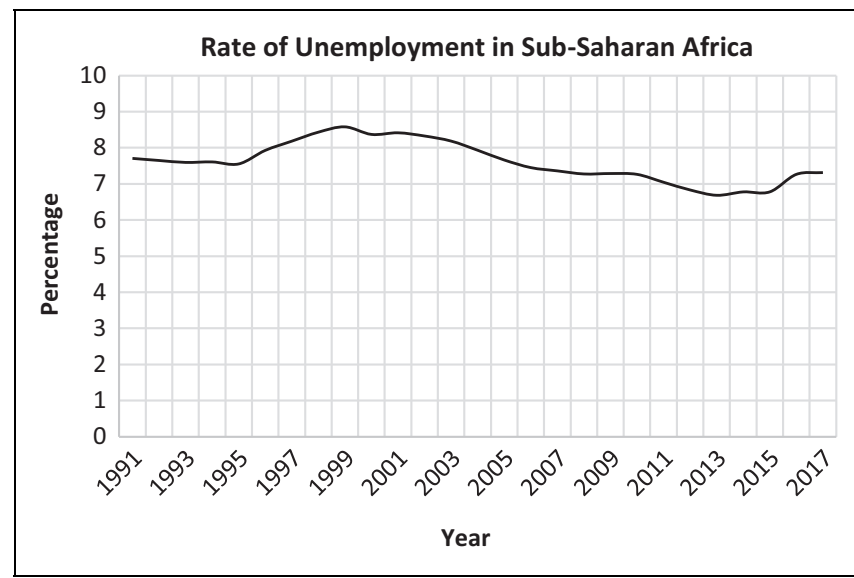

Source - The World Bank.

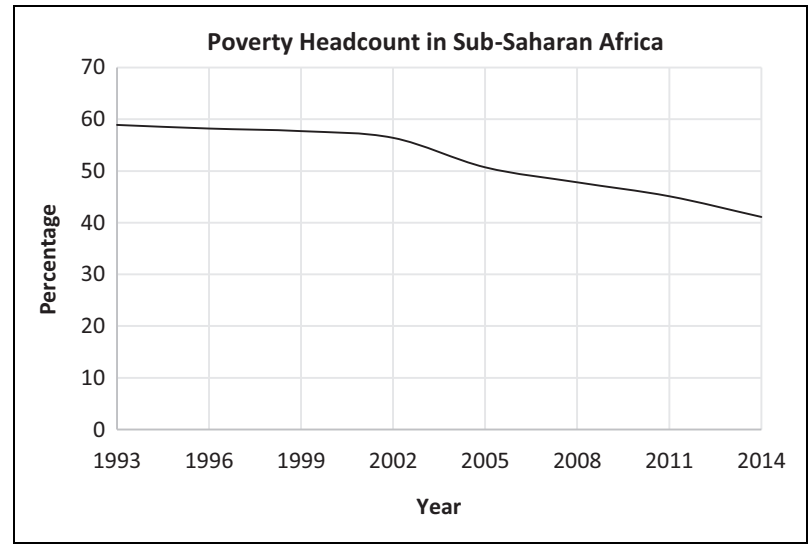

Source - The World Bank.

\section{Acknowledgments}

The authors are indebted to the editor, the special issue editor(s), and three anonymous reviewers for their feedback and valuable comments.

\section{Declaration of Conflicting Interests}

The author(s) declared no potential conflicts of interest with respect to the research, authorship, and/or publication of this article.

\section{Funding}

The author(s) received no financial support for the research, authorship, and/or publication of this article.

\section{ORCID iDs}

Eldrede Kahiya (D) https://orcid.org/0000-0001-8499-4222 Djavlonbek Kadirov (D) https://orcid.org/0000-0001-7618-6903

\section{References}

African Development Bank (2015), "Growth, Poverty, and Inequality Nexus: Overcoming Barriers to Sustainable Development,"
African Development Report, African Development Bank Group, number 2342, Abidjan, Ivory Coast.

Afrika, Jean-Guy K. and Gerald Ajumbo (2012), "Informal Cross Border Trade in Africa: Implications and Policy Recommendations," Africa Development Bank - Africa Economic Brief, 3 (10), 1-13.

Akinboade, Oludele A. (2005), "A Review of Women, Poverty and Informal Trade Issues in East and Southern Africa," International Social Science Journal, 57 (184), 255-75.

Alusala, Nelson (2010), "Informal Cross-Border Trade and Arms Smuggling along the Uganda-Rwanda Border," African Security Review, 19 (3), 15-26.

Ama, Njoku O., Kagiso T. Mangadi, and Helen A. Ama (2014), "Exploring the Challenges Facing Women Entrepreneurs in Informal Cross-Border Trade in Botswana," Gender in Management: An International Journal, 29 (8), 505-22.

Arellano, Rolando (1994), "Informal-Underground Retailers in LessDeveloped Countries: An Exploratory Research from a Marketing Point of View," Journal of Macromarketing, 14 (2), 21-35.

Aung, Winston S. (2009), "The Role of Informal Cross-Border Trade in Myanmar," Institute for Security and Development Policy, Singapore, (accessed October 07, 2018), [available at http://isdp.eu/ content/uploads/publications/2009_set-aung_the-role-of-informalcross-border-trade.pdf].

Ayadi, Lotfi, Nancy Benjamin, Sami Bensassi, and Gaël Raballand (2013), "Estimating Informal Trade across Tunisia's Land Borders," Policy and Research Working Paper, 6731, The World Bank, Middle East and North Africa Region, (accessed February 12, 2019), [available at https://elibrary.worldbank.org/doi/pdf/10. 1596/1813-9450-6731].

Babah, Daouda, Falylath Paul T. M. Ingenbleek, and Hans C. M. van Trijp (2019), "Living the African Dream: How Subsistence Entrepreneurs Move to Middle-Class Consumer Markets in Developing and Emerging Countries," Journal of Public Policy \& Marketing, 38 (1), 42-60.

Beninger, Stefanie and Stanley J. Shapiro (2019), “A Historical Review of Local Intermediaries in Impoverished Contexts," Journal of Macromarketing, 39 (3), 238-51.

Benjamin, Nancy, Stephen Golub, and Ahmadou A. Mbaye (2015), "Informality, Trade Policies and Smuggling in West Africa," Journal of Borderlands Studies, 30 (3), 381-94.

Blankson, Charles, Kirsten Cowan, and William K. Darley (2018), "Marketing Practices of Rural Micro and Small Businesses in Ghana: The Role of Public Policy," Journal of Macromarketing, 38 (1), 29-56.

Blumberg, Rae L., Joyce Malaba, and Lis Meyers (2016), "Women Cross Border Traders in Southern Africa: Contributions, Constraints, and Opportunities in Malawi and Botswana," Prepared by AECOM International Development \& Banyan Global for USAID Southern Africa, (accessed July 14, 2018), [available at https://banyanglobal.com/wp-content/uploads/2017/05/ICBT-Gen der-Assessment-Report_Final_4-30-2016_DEC.pdf].

Briner, Rob B., David Denyer, and Denise M. Rousseau (2009), “Evidence-Based Management: Concept Clean-Up Time?" Academy of Management Perspectives, 23 (4), 19-32.

Britan, Gerald M. and Ronald Cohen (1980), "Toward an Anthropology of Formal Organizations," in Hierarchy and Society, Gerald 
M. Britan and Ronald Cohen, eds. Philadelphia: Institute for the Study of Human Issues, 9-30.

Chandler, Jennifer D. and Stephen L. Vargo (2011), "Contextualization and Value-in-Context: How Context Frames Exchange," Marketing Theory, 11 (1), 35-49.

Chen, Martha A. (2007), "Rethinking the Informal Economy: Linkages with the Formal Economy and the Formal Regulatory Environment," DESA Working Paper No. 46, United Nations Department of Economic and Social Affairs, New York, (accessed July 11, 2018), [available at https://www.un.org/esa/desa/papers/ 2007/wp46_2007.pdf].

Churchman, C. West (1967), "Guest Editorial: Wicked Problems," Management Science, 14 (4), 141-42.

Conklin, Jeff (2006), Wicked Problems \& Social Complexity. San Francisco, CA: CogNexus Institute.

Creswell, John W. (2002), Educational Research: Planning, Conducting, and Evaluating Quantitative and Qualitative Research. Upper Saddle River, NJ: Pearson Education.

Crittenden, Victoria L. and Robert A. Peterson (2013), "Scientific Progress in Marketing," AMS Review, 3 (1), 1-2.

Crush, Jonathan and Bruce Frayne (2011), "Supermarket Expansion and the Informal Food Economy in Southern African Cities: Implications for Urban Food Security," Journal of Southern African Studies, 37 (4), 781-807.

Dadzie, Kofi Q., Ishmael P. Akaah, and Bruce H. Dunson (1989), "Promoting the Bank Savings Habit in Ghana: A Success in Marketing Technology Transfer," Journal of Macromarketing, 9 (1), 16-23.

Dadzie, Kofi Q., Charlene A. Dadzie, Evelyn M. Winston, and Charles Blankson (2013), "Inclusive Economic Development Programs and Consumers' Access to Credit in Emerging Market Economies: The Public Policy Role of Marketing in Rural Bank Programs in Ghana," Journal of Public Policy and Marketing, 32 (Special Issue), 59-69.

Darley, William K. and Charles Blankson (2008), "African Culture and Business Markets: Implications for Marketing Practices," Journal of Business and Industrial Marketing, 23 (6), 374-83.

Desai, Manisha (2009), "Women Cross-Border Traders: Rethinking Global Trade," Development, 52 (3), 377-86.

Dobler, Gregor (2016), "The Green, the Grey and the Blue: A Typology of Cross-Border Trade in Africa," Journal of Modern African Studies, 54 (1), 145-69.

Ellis, Stephen and Janet MacGaffey (1996), "Research on SubSaharan Africa's Unrecorded International Trade: Some Methodological and Conceptual Problems," African Studies Review, 39 (2), 19-41.

Fadahunsi, Akin (2000), "Researching Informal Entrepreneurship in Sub-Saharan Africa: A Note on Field Methodology," Journal of Developmental Entrepreneurship, 5 (3), 249-60.

Fadahunsi, Akin and Peter Rosa (2002), "Entrepreneurship and Illegality: Insights from the Nigerian Cross-Border Trade," Journal of Business Venturing, 17 (5), 397-429.

Fisk, George (1967), Marketing Systems: An Introductory Analysis. New York: Harper \& Row.

Fisk, George (2006), "Envisioning a Future for Macromarketing," Journal of Macromarketing, 26 (2), 214-18.
Flynn, Donna K. (1997), ““We are the Border”: Identity, Exchange, and the State along the Benin-Nigeria Border," American Ethnologist, 24 (2), 311-30.

Gaughan, Joseph P. and Louis A. Ferman (1987), "Toward an Understanding of the Informal Economy," The Annals of the American Academy of Political and Social Science, 493 (1), 15-25.

Golub, Stephen (2015), "Informal cross-border trade and smuggling in Africa," in Handbook on Trade and Development, Oliver Morrissey, Ricardo López, and Kishor Sharma, eds. Cheltenham: Edward Elgar, 179-209.

Hastings, Justin V. and Yaohui Wang (2018), "Informal Trade along the China-North Korea Border," Journal of East Asian Studies, 18 (2), 181-203.

Herrington, Mike and Donna Kelly (2012), “African Entrepreneurship: Sub-Saharan African Regional Report," Global Entrepreneurship Monitor, International Development Research Centre, (accessed October 15, 2018), [available at https://www.gemconsor tium.org/report/48601].

Hofstede, Geert (1980), Culture's Consequences: International Differences in Work-related Values. Beverly Hills, CA: Sage.

Hounhouigan, Menouwesso H., Paul T. M. Ingenbleek, Ivo A. Van der Lans, Hans C. M. van Trijp, and Anita R. Linnemann (2014), "The Adaptability of Marketing Systems to Interventions in Developing Countries: Evidence from the Pineapple System in Benin," Journal of Public Policy \& Marketing, 33 (2), 159-72.

Hunter, Nina and Caroline Skinner (2003), "Foreign Street Traders Working in Inner City Durban: Local Government Policy Challenges," Urban Forum, 14 (4), 301-19.

Kadirov, Djavlonbek (2018), "Towards a Theory of Marketing Systems as the Public Good," Journal of Macromarketing, 38 (3), 278-97.

Kahiya, Eldrede and Rebecca Kennedy (2016), "Regulative Environment and Entrepreneurial Activity: Insights from Sub-Saharan Africa," in Handbook of Entrepreneurship in Developing Countries, Colin Williams and Anjula Gurto, eds. New York: Routledge, 54-69.

Koroma, Suffyan, Joan Nimarkoh, Ny You, Victor Ogalo, and Boniface Owino (2017), "Formalization of Informal Trade in Africa: Trends, Experiences and Socio-Economic Impacts," CUTS International - Food and Agriculture Organizations of the United Nations, Regional Office for Africa, Ghana, (accessed October 04, 2018), [available at http://www.fao. org/3/a-i7101e.pdf].

Kotler, Philip, Ned Roberto, and Tony Leisner (2006), "Alleviating Poverty: A Macro/micro marketing Perspective," Journal of Macromarketing, 26 (2), 233-39.

Kumar, V. (2015), "Evolution of Marketing as a Discipline: What has Happened and What to Look Out For," Journal of Marketing, 79 (1), 1-9.

Layton, Roger A. (2007), "Marketing Systems - A Core Macromarketing Concept," Journal of Macromarketing, 27 (3), 227-42.

Layton, Roger A. (2011), "Towards a Theory of Marketing Systems," European Journal of Marketing, 45 (1/2), 259-76.

Layton, Roger A. (2015), "Formation, Growth, and Adaptive Change in Marketing Systems," Journal of Macromarketing, 35 (3), 302-19. 
Layton, Roger A. and Sanford Grossbart (2006), "Macromarketing: Past, Present, and Possible Future," Journal of Macromarketing, 26 (2), 193-213.

Leech, Nancy L. and Anthony J. Onwuegbuzie (2007), “An Array of Qualitative Data Analysis Tools: A Call for Data Analysis Triangulation," School Psychology Quarterly, 22 (4), 557-84.

Lesser, Caroline and Evdokia Moisé-Leeman (2009), "Informal Cross-Border Trade and Trade Facilitation Reform in SubSaharan Africa," OECD Trade Policy Paper No. 86, OECD Publishing, Paris, (accessed October 20, 2018), [available at https:// www.oecd-ilibrary.org/trade/informal-cross-border-trade-andtrade-facilitation-reform-in-sub-saharan-africa_225770164564]. doi: $10.1787 / 225770164564$.

Lindeman, Sara (2014), ““Until We Live Like they Live in Europe”: A Multilevel Framework for Community Empowerment in Subsistence Markets," Journal of Macromarketing, 34 (2), 171-85.

Little, Peter D. (1992), "Traders, Brokers and Market 'Crisis' in Southern Somalia," Africa - Journal of International African Institute, 62 (1), 94-124.

Little, Peter D., Waktole Tiki, and Dejene N. Debsu (2015), “Formal or Informal, Legal or Illegal: The Ambiguous Nature of CrossBorder Livestock Trade in the Horn of Africa," Journal of Borderlands Studies, 30 (3), 405-21.

Lomnitz, Larissa A. (1988), "Informal Exchange Networks in Formal Systems: A Theoretical Model," American Anthropologist, 90 (1), 42-55.

MacInnis, Debra J. (2011), “A Framework for Conceptual Contributions in Marketing," Journal of Marketing, 75 (4), 136-54.

MacLure, Maggie (2005), “'Clarity Bordering on Stupidity': Where's the Quality in Systematic Review?" Journal of Education Policy, 20 (4), 393-416.

Manjokoto, Caroline and Dick Ranga (2017), “Opportunities and Challenges Faced by Women Involved in Informal Cross-Border Trade in the City of Mutare During a Prolonged Economic Crisis in Zimbabwe," Journal of the Indian Ocean Region, 13 (1), 25-39.

Mawejje, Joseph and Dorothy Nampewo (2018), "Food Prices, Money Growth and Informal Cross-Border Trade: Evidence from Uganda," African Journal of Economic and Management Studies, 9 (1), $72-87$.

McArthur, Ellen, Scott Weaven, and Rajiv Dant (2016), "The Evolution of Retailing: A Meta Review of the Literature," Journal of Macromarketing, 36 (3), 272-86.

Meagher, Kate (2003), "A Back Door to Globalization? Structural Adjustment, Globalization \& Transborder Trade in West Africa," Review of African Political Economy, 30 (95), 57-75.

Mercandalli, Sara and Bruno Losch, eds. (2017), "Rural Africa in Motion: Dynamics and Drivers of Migration South of the Sahara," FAO and CIRAD, Rome, (accessed September 10, 2018), [available at http://www.fao.org/3/I7951EN/i7951en.pdf].

Mohamadain, ElTayeb and Hassan Ahmed A. Ati (2015), "Informal Cross-Border Trade in Eastern Sudan: A Case Study from Kassala and Gedarif States," Sudan Working Paper SWP 2015:6, CHR. Michelsen Institute, University of Bergen, Norway, (accessed August 8,2018 ), [available at https://www.cmi.no/publications/ 5668-informal-cross-border-trade-in-eastern-sudan-a].
Murdock, George P. (1967), "Ethnographic Atlas: A Summary," Ethnology, 6 (2), 109-236.

Muzanenhamo, Penelope (2019), "What Does Africapitalism have to do with Brand Africa?" in Africapitalism: Sustainable Business and Development in Africa, Idemudia Uwafiokun and Kenneth Amaeshi, eds. New York: Routledge, 166. doi:https://doi.org/10. 4324/9781315559346.

Muzvidziwa, Victor N. (1998), "Cross-Border Trade: A Strategy for Climbing out of Poverty in Masvingo, Zimbabwe," Zambezia, 25 (1), 29-58.

Muzvidziwa, Victor (2001), "Zimbabwe's Cross-Border Women Traders: Multiple Identities and Responses to New Challenges," Journal of Contemporary African Studies, 19 (1), 67-80.

Ndlela, Daniel B. (2006), "Informal Cross-Border Trade: The Case of Zimbabwe," Institute for Global Dialogue, South Africa (accessed July 22, 2018), [available at https://www.jstor.org/stable/ resrep07751].

Newman, Christopher L., Anna M. Turri, Elizabeth Howlett, and Amy Stokes (2014), "Twenty years of Country-of-Origin Food Labelling Research: A Review of the Literature and Implications for Food Marketing Systems," Journal of Macromarketing, 34 (4), 505-19.

Nkendah, Robert (2013), "Estimating the Informal Cross-Border Trade of Agricultural and Horticultural Commodities between Cameroon and its CEMAC Neighbours," Food Policy, 41 (2013), 133-44.

Nshimbi, Christopher C. (2019), "Life in the Fringes: Economic and Sociocultural Practices in the Zambia-Malawi-Mozambique Borderlands in Comparative Perspective," Journal of Borderlands Studies, 34 (1), 47-70.

Nshimbi, Christopher C. (2015), "Networks of Cross-Border NonState Actors: The Role of Social Capital in Regional Integration," Journal of Borderlands Studies, 30 (4), 537-60.

Ntseane, Peggy (2004), "Being a Female Entrepreneur in Botswana: Cultures, Values, Strategies for Success," Gender \& Development, 12 (2), 37-43.

Ogalo, Victor (2010), "Informal Cross-Border Trade in EAC: Implications for Regional Integration and Development," CUTS African Resource Centre, Nairobi, (accessed May 11, 2018), [available at http://www.cuts-geneva.org/pdf/BIEAC-RP10-How_Might_ EAC_Reduce_Negative_Implications.pdf].

Ostrom, Elinor (2005), Understanding Institutional Diversity. Princeton, NJ: Princeton University Press.

Papadopoulos, Nicolas and Shavin Malhotra (2007), "Export Processing Zones in Development and International Marketing: An Integrative Review and Research Agenda," Journal of Macromarketing, 27 (2), 148-61.

Paul, Justin and Erick Mas (2019), “Toward a 7-P Framework for International Marketing," Journal of Strategic Marketing, (accessed August 12, 2019), [available at https://www.tandfon line.com/doi/full/10.1080/0965254X.2019.1569111]. doi:10. 1080/0965254X.2019.1569111, 1-21.

Peberdy, Sally A. (2000a), "Mobile Entrepreneurship: Informal Sector Cross-Border Trade and Street Trade in South Africa," Development Southern Africa, 17 (2), 201-19. 
Peberdy, Sally A. (2000b), "Border Crossings: Small Entrepreneurs and Cross-Border Trade between South Africa and Mozambique," Tijdschrift voor economische en sociale geografie, 91 (4), 361-78.

Peberdy, Sally A. and Jonathan Crush (2001), "Invisible Trade, Invisible Travellers: The Maputo Corridor Spatial Development Initiative and Informal Cross-Border Trading," South African Geographical Journal, 83 (2), 115-23.

Peberdy, Sally A. and Christian Rogerson (2000), "Transnationalism and Non-South African Entrepreneurs in South Africa's Small, Medium and Micro-Enterprise (SMME) Economy," Canadian Journal of African Studies, 34 (1), 20-40.

Peterson, Mark (2006), "Focusing the Future of Macromarketing," Journal of Macromarketing, 26 (2), 245-49.

Peterson, Mark, Saman S., and Zehra (2018), "Putting African Country Development into Macromarketing Perspective," in Emerging Issues in Global Marketing, James Agarwal and Terry Wu, eds. Cham: Springer, 333-368. doi:10.1007/978-3-319-74129-1_13.

Pisani, Michael J. and Chad Richardson (2012), "Cross-Border Informal Entrepreneurs across the South Texas-Northern Mexico Boundary," Entrepreneurship \& Regional Development, 24 (3-4), 105-21.

Prahalad, Coimbatore K. and Allen Hammond (2002), "Serving the World's Poor, Profitably," Harvard Business Review, 80(9), 48-59.

Raeymaekers, Timothy (2012), "Reshaping the State in its Margins: The State, the Market and the Subaltern on a Central African Frontier," Critique of Anthropology, 32 (3), 334-50.

Rittel, Horst W. and Melvin M. Webber (1973), "Dilemmas in a General Theory of Planning," Policy Sciences, 4 (2), 155-69.

Rousseau, Denise M., Joseph Manning, and David Denyer (2008), "Evidence in Management and Organizational Science: Assembling the Field's Full Weight of Scientific Knowledge through Syntheses," Academy of Management Annals, 2 (1), 475-515.

Shimuafeni, Alex (2015), "Informal Cross Border Trade Statistics," September 2015, Namibia Statistics Agency, (accessed August 2018), [available at http://cms.my.na/assets/documents/Informal_ Cross_Border_Trade_Sep_2015.pdf].

Singh, Ramendra and Apoorva Bharadwaj (2017), "BOP Research Meets Macromarketing: Content Analysis of BOP-Related Research in the Journal of Macromarketing," Decision, 44 (1), 69-82.

Sridharan, Srinivas, Elliot Maltz, Madhubalan Viswanathan, and Samir Gupta (2014), "Transformative Subsistence Entrepreneurship: A Study in India," Journal of Macromarketing, 34 (4), 486-504.

Sword, Keith (1999), "Cross-Border 'Suitcase Trade' and the Role of Foreigners in Polish Informal Markets," in The Challenge of EastWest Migration for Poland, Keith Sword and Krystyna Iglicka, eds. London, UK: Palgrave Macmillan, 145-167.

Taneja, Nisha and Samridhi Bimal (2017), "India's Informal Trade with Pakistan," in India-Pakistan Trade Normalisation: The Unfinished Economic Agenda, Nisha Taneja and Isha Dayal, eds. Singapore: Springer, 245-269. doi:10.1007/978-981-10-2215-9_8.

The Economist (2018), "Informal Trade is Ubiquitous in Africa - But too often Ignored," (accessed July 17, 2018), [available at https:// www.economist.com/finance-and-economics/2018/09/01/infor mal-trade-is-ubiquitous-in-africa-but-too-often-ignored].
Thomas, David R. (2006), “A General Inductive Approach for Analyzing Qualitative Evaluation Data," American Journal of Evaluation, 27 (2), 237-46.

Titeca, Kristof (2012), "Tycoons and Contraband: Informal CrossBorder Trade in West Nile, North-Western Uganda," Journal of Eastern African Studies, 6 (1), 47-63.

Titeca, Kristof (2018), ““'Illegal Ivory Trade as Transnational Organized Crime?" An Empirical Study into Ivory Traders in Uganda," The British Journal of Criminology, 59 (1), 24-44.

Titeca, Kristof and Rachel Flynn (2014), ““'Hybrid Governance,” Legitimacy, and (Il)legality in the Informal Cross-Border Trade in Panyimur, Northwest Uganda," African Studies Review, 57 (1), 71-91.

Titeca, Kristof and Célestin Kimanuka (2012), Walking in the Dark: Informal Cross-Border Trade in the Great Lakes Region. London, UK: International Alert and UN Women.

Tranfield, David, David Denyer, and Palminder Smart (2003), "Towards a Methodology for Developing Evidence-Informed Management Knowledge by Means of Systematic Review," British Journal of Management, 14 (3), 207-22.

Tschirley, David L. and Thomas S. Jayne (2010), "Exploring the Logic behind Southern Africa's Food Crises," World Development, 38 (1), 76-87.

Van den, Boogaard, Vanessa Wilson Prichard, and Samuel Jibao (2018), "Norms, Networks, Power and Control: Understanding Informal Payments and Brokerage in Cross-Border Trade in Sierra Leone," Journal of Borderlands Studies, (accessed May 15, 2019), [available at https://www.tandfonline.com/doi/full/10.1080/ 08865655.2018.1510333]. doi:10.1080/08865655.2018.1510333.

Walther, Olivier (2009), “A Mobile Idea of Space: Traders, Patrons and the Cross-Border Economy in Sahelian Africa," Journal of Borderlands Studies, 24 (1), 34-46.

Walther, Olivier (2012), "Traders, Agricultural Entrepreneurs and the Development of Cross-Border Regions in West Africa," Entrepreneurship \& Regional Development, 24 (3-4), 123-41.

Welter, Friederike, Ted Baker, David Audretsch B., and William Gartner B. (2017), "Everyday Entrepreneurship - A Call for Entrepreneurship Research to Embrace Entrepreneurial Diversity", Entrepreneurship Theory and Practice, 41 (3), 311-21.

Williams, Colin C. and Sara Nadin (2010), "Entrepreneurship and the Informal Economy: An Overview," Journal of Developmental Entrepreneurship, 15 (4), 361-78.

Wooliscroft, Ben (2016), "Introduction to the Special Issue on Research Methodologies for Macromarketing: Macromarketing Research: It's Not Rocket Science ... it's Much Harder," Journal of Macromarketing, 36 (1), 8-10.

World Economic Forum (2018), "The Inclusive Development Index 2018; Summary and Data Highlights," World Economic Forum, Geneva, Switzerland, (accessed October 21, 2018), [available at http://www3.weforum.org/docs/WEF_Forum_IncGrwth_2018.pdf].

World Food Programme (2007), "Informal Cross Border Food Trade in Southern Africa", (accessed October 15, 2018), [available https:/documents.wfp.org/stellent/groups/public/documents/ena/ wfp201342.pdf?iframe].

Wrigley-Asante, Charlotte (2013a), "Unravelling the Health-Related Challenges of Women in the Informal Economy: Accounts of 
Women in Cross-Border Trading in Accra, Ghana," GeoJournal, 78 (3), 525-37.

Wrigley-Asante, Charlotte (2013b), "Survival or Escaping Poverty: The Perspectives of Poverty and Well-Being among Ghanaian Women in Cross-Border Trading," Journal of Gender Studies, 22 (3), 320-34.

Xheneti, Mirela, David Smallbone, and Friederike Welter (2013), "EU Enlargement Effects on Cross-Border Informal Entrepreneurial Activities," European Urban and Regional Studies, 20 (3), 314-28.

Yadav, Manjit S. (2010), "The Decline of Conceptual Studies and Implications for Knowledge Development," Journal of Marketing, 74 (1), 1-19.

Yusuff, S. Olabisi (2014), "Gender Dimensions of Informal Cross Border Trade in West-African Sub-Region (ECOWAS) Borders," International Letters of Social and Humanistic Sciences, 29 (2014), 19-33.

\section{Author Biographies}

Eldrede Kahiya (MBA, PhD) is a Senior Lecturer in the School of Marketing and International Business, Victoria University of
Wellington, New Zealand. His research examines entrepreneurial internationalization or export activities of small and medium-size businesses, and blends International Business and International Entrepreneurship. Eldrede's work has appeared in journals such as International Business Review, European Business Review, Journal of International Entrepreneurship, and Asia Pacific Journal of Marketing and Logistics. He is the Australia-New Zealand ambassador for the International Entrepreneurs network.

Djavlonbek Kadirov ( $\mathrm{PhD}$, University of Waikato) is a Senior Lecturer in the School of Marketing and International Business, Victoria University of Wellington, New Zealand. Djavlonbek's research interests include marketing systems theory, symbolism in marketing systems, sustainable marketing, and marketing morality. His research has appeared in journals such as the Journal of Macromarketing, Journal of Marketing Management, Journal of Business Research, Journal of Brand Management, Consumption Markets \& Culture, and Journal of Customer Behavior. Djavlonbek (along with Richard Varey and Ben Wooliscroft) is the winner of the George Fisk Award for the Best Conference Paper at the 2013 Macromarketing Conference. 